\title{
Field of application of high strength steel circular tubes for steel and composite columns from an economic point of view
}

\author{
Hoang Van Long, Demonceau Jean-François, Ly Dong Phuong Lam, Rossi Barbara \\ ArGEnCo Department, University of Liège, Belgium
}

\begin{abstract}
This paper presents the results of a global comparison between high strength steel and normal steel circular tube used to build steel and composite columns submitted to static loading, in regards with the economic aspects. The comparison is based on an optimum design taking into account the strength, stability and stiffness conditions of Eurocode 3 and 4. The automatic implementation of the algorithms allows achieving a high amount of case studies, covering the realistic possibilities of build columns. The investigations are realized on simple columns, columns included in braced or un-braced frames and whole frames. The field of application of high strength steel (vs normal steel), regarding the total cost of the member, is provided in a chart clearly indicating where the use of high strength steel becomes economic.
\end{abstract}

Key words: Economic interest; High strength steel; Column; Steel frame; Composite frame; Circular tube; Optimum design.

\section{Introduction}

High strength steel is the term generally employed for steel presenting a proof strength higher than 450MPa. The use of high strength steel (HSS) in load-bearing structures has fairly during the last decades thanks to its advantages as underlined by authors in $[1,6,7,9]$. The reason lays not only but mainly in its economic interest compared to steel, whose cost increases slower than its strength. However, as the stiffness of HSS structures is smaller than the one of normal steel (NS) structures, the second-order effects and the serviceability requirements considerably limit the use of HSS in load-bearing structures.

But this question has been sporadically considered in the researches concerning the behaviour of structures made of HSS. Therefore, the economic profit of using HSS in constructions needs to be more adequately studied in order to highlight the advantages of HSS in each type of structures. The present work aims at investigating steel and composite construction using circular steel tubes for the columns. The objective is to define the two respective domains where HSS and NS respectively are of economic interest. Two points will be simultaneously reported: (1) provide a general view of the economic benefit of the use of HSS; (2) establish the basis for choosing the material (HSS or NS) for framed structures before designing it.

The present research compares the costs of two columns made of HSS and NS. Steel with yield strengths varying from $500 \mathrm{~N} / \mathrm{mm}^{2}$ to $700 \mathrm{~N} / \mathrm{mm}^{2}$ will be considered as HSS [4] while S355 steel is considered as NS. The strength, stability and stiffness conditions according to Part 1-1 of Eurocode 3 [3] and Part 1-1 of Eurocode 4 [5] will be taken into account in the optimum cost design for steel and composite columns. Concerning the analysis of structures made of HSS, the rules of Part 1-12 of Eurocode 3 will be used [4]. Simple columns, columns in braced/un-braced frames and general frames will be investigated. In each case, the algorithms are implemented and the resulting automatic calculation allows examining almost practical possibilities.

\section{Investigation for simple columns}

Let us consider a simple column as the one depicted in Fig.1. The cost of two solutions with the same length and under the same loading but using two different steel grades, NS and HSS, is evaluated. In order to be comparable, the optimum cost design for each column is needed (Section 
2.1). Afterwards, a global comparison is made in order to evaluate which grade is of economic interest (Section 2.2). An adequate number of case studies to be carried out is then chosen in order that the global study provides general results (Section 2.3). The conclusions for simple columns are provided in Section 2.4.

\subsection{Optimum cost design for single columns}

The optimum cost design provides the cheapest structure among the admissible solutions respecting the necessary safety conditions. Generally, an optimum cost design consists of three main steps: (1) the application of the rules controlling the safety of the structure that will be the constraints of the optimal problem (Sections 2.1.1 and 2.1.2); (2) the establishment of the cost function representing the objective to be minimized (Section 2.1.3); (3) the arrangement of the problem under mathematical optimal procedure, and the choice of a suitable algorithm to solve the problem (Section 2.1.3).

\subsubsection{Safety condition for steel columns}

The very widespread safety rules of Eurocode-3 [3] are used in the present work. Only a few recalls necessary for the good comprehension of the reader are provided below.

- The input quantities are:

- $f_{\mathrm{y}}$ is the characteristic $(\mathrm{k}) /$ design (d) value of the yield strength;

- $E$ is the modulus of elasticity of the steel; $E=2,1 \times 10^{9} \mathrm{kN} / \mathrm{m}^{2}$ is taken in the present work;

- $\mathrm{D}$ is the outside diameter of the tube;

- $\mathrm{t}$ is the tube thickness;

- $l$ is the length of the column, it is also the buckling length in this case.

- $N_{E d}, M_{E d}$ are the respective design values of the axial load and the bending moment. If the bending moment is not uniform, the equivalent moment is used.

-Classification of sections:

$$
\mid \begin{array}{ll}
D / t \leq 50 \varepsilon^{2}: & \text { Class } 1 \\
D / t \leq 70 \varepsilon^{2}: & \text { Class } 2 \\
D / t \leq 90 \varepsilon^{2}: & \text { Class } 3
\end{array}
$$

where $\varepsilon=\sqrt{235 / f_{y}}$ if $f_{\mathrm{y}}$ is expressed in $\mathrm{N} / \mathrm{mm}^{2}$.

Class 4 is not considered in the present work.

-The intermediate quantities:

- $A=\pi\left(t^{2}+D t\right)$ is the cross-section area;

$-W_{e l}=\frac{\pi}{32 d}\left[D^{4}-(D-2 t)^{4}\right]$ is the elastic section modulus;

- $W_{p l}=\frac{1}{6}\left[D^{3}-(D-2 t)^{3}\right]$ is the plastic section modulus;

- $I=\frac{\pi}{64}\left[D^{4}-(D-2 t)^{4}\right]$ is the second moment of inertia of the cross-section;

- $N_{p}=f_{y} A$ is the design plastic compression resistance; 
- $M_{e l}=f_{y} W_{e l}$ is the design elastic bending resistance;

- $M_{p l}=f_{y} W_{p l}$ is the design plastic bending resistance;

$-i=\sqrt{\frac{I}{A}}$ is the radius of gyration of the cross-section;

- $\bar{\lambda}=\sqrt{\frac{N_{p l}}{N_{c r}}}=\frac{l}{\pi i} \sqrt{\frac{f_{y}}{E}}$ is the non-dimensional slenderness of the column where the elastic buckling force is provided in Eq. (2);

$$
N_{c r}=\frac{\pi^{2} E I}{l^{2}}
$$

- $\Phi=0,5\left[1+\alpha(\bar{\lambda}-0,2)+\bar{\lambda}^{2}\right]$ is used to determine the reduction factor $\chi$, with: $\alpha=0,21$ for S355 and $\alpha=0,13$ for HSS, the tubes are supposed to be hot finished. The reduction factor is calculated using Eq. (3);

$$
\chi=\frac{1}{\Phi+\sqrt{\Phi^{2}-\bar{\lambda}^{2}}}
$$

- $C_{y y}$ is the factor taking into account the reduction of the design plastic resistance due to axial force:

$$
\begin{aligned}
C_{y y} & =1 \\
C_{y y} & =\mid \begin{array}{lll}
1,1 \quad \text { if } \quad \bar{\lambda} \leq 1 & \text { for section of Class } 3 ; \\
1 /\left[0,9+0,5\left(W_{p l} / W_{e l}-0,9\right)(\bar{\lambda}-1)\right. & \text { if } \quad 1<\bar{\lambda} \leq 3 & \text { for section of Class } 1 \text { or } 2 . \\
\left(W_{p l} / W_{e l}\right)^{-1} & \text { if } \quad \lambda>3 &
\end{array}
\end{aligned}
$$

- $M_{R k}$ is the characteristic bending resistance of the critical cross-section: with sections of

Class 1 and Class 2: $M_{R k}=M_{p l}$; with sections of Class 3: $M_{R k}=M_{e l}$.

- Member verification:

$$
\frac{N_{E d}}{\chi N_{p}}+\frac{1}{1-\frac{\chi N_{E d}}{N_{c r}}} \frac{M_{E d}}{C_{y y} M_{R k}} \leq 1
$$

\subsubsection{Safety condition for composite columns}

The rules of Eurocode-4 [5] for composite columns are summarized in this Section.

-The input quantities:

- $f_{y}$ is the characteristic $(\mathrm{k}) /$ design (d) value of the yield strength of the steel tube;

- $f_{c k}, f_{c d}$ are the characteristic value and the design value of the strength of the concrete;

- $f_{s k}, f_{s d}$ are the characteristic value and the design value of the strength of the rebar; 
- $E_{a}, E_{c}, E_{s}$ are the modulus of elasticity of the steel, the concrete and the rebar. The values of $E_{c}=3,2 \times 10^{8} \mathrm{kN} / \mathrm{m}^{2}$ and $E_{s}=2,1 \times 10^{9} \mathrm{kN} / \mathrm{m}^{2}$ are used in the present work.

- $\mathrm{D}$ is the outside diameter of steel tube;

- $\mathrm{t}$ is the tube thickness;

- $b$ is the distance from the centre of the rebar to the inside face of the tube (Fig.1);

- $l$ is the length of the column, it is also the effective length in this case.

- $N_{E d}, M_{E d}$ are the design values of the axial load and of the bending moment.

\section{- Strength of the cross-section (Interaction curve)}

Due to the non-symmetry of the stress-strain response of concrete under tension and compression, the shape of the interaction curve for composite sections is similar to the curve shown in Fig.2, with the particular points: A, B, C and D. With circular sections, the volume of computation to determine this curve by hand is quite large. Thus, in order to be able to implement the equations for automatic calculations, the following assumption is made (Figs. 3a and 3b): the area of reinforcements is supposed to be a continuous ring instead of distinct rebars. The ensuing error decreases when the number of rebars increases.

Using the symbols reported in Fig.3, all the following quantities can be expressed using the location of the neutral axis that only depends on the angle $\theta_{1}$ (Figs.3c and 3d):

$$
\begin{gathered}
r_{3}=\left(r_{2}-b\right)+\frac{A_{s}}{4 \pi\left(r_{2}-b\right)} ; \\
r_{4}=\left(r_{2}-b\right)-\frac{A_{s}}{4 \pi\left(r_{2}-b\right)} ; \\
\theta_{i}=\begin{array}{c}
\arctan \frac{r_{1} \sin \theta_{1}}{\sqrt{r_{i}^{2}-\left(r_{1} \sin \theta_{1}\right)^{2}}} \text { if } r_{i}^{2}-\left(r_{1} \sin \theta_{1}\right)^{2}>0 \\
\pi / 2 \text { if } r_{i}^{2}-\left(r_{1} \sin \theta_{1}\right)^{2} \leq 0 \\
A_{i}=r_{i}^{2}\left(\pi / 2-\theta_{i}-\sin \theta_{i} \cos \theta_{i}\right) ; \\
N_{\theta_{1}}=\left(A_{a}+2 A_{2}-2 A_{1}\right) f_{y d}+\left(A_{c}+A_{3}-A_{2}-A_{4}\right) f_{c d}+\left(A_{s}+2 A_{4}-2 A_{3}\right) f_{s d} ; \\
M_{\theta_{1}}=\left(S_{1}-S_{2}\right) f_{y d}+\left(S_{2}-S_{3}+S_{4}\right) f_{c d}+\left(S_{3}-S_{4}\right) f_{s d} .
\end{array}
\end{gathered}
$$

Let $\theta_{1}$ vary from $-\pi / 2$ to $\pi / 2$, using Eqs. (5) and (6), it is possible to depict the interaction curve (from A' to A of Fig.3.f) containing the particular points A, B, C, D (Figs. 3e and 3f):

- Point A corresponds to $\theta_{1}=\pi / 2$;

- Point B corresponds to $\theta_{1}=\theta^{*} ; \theta^{*}$ is determined by Eq.(5), but $N_{\theta^{*}}=0$;

- Point D corresponds to $\theta_{1}=0$; 
- Point $\mathrm{C}$ is deduced by points $\mathrm{B}$ and $\mathrm{D}$.

In the case of no reinforcements, $A_{s}=0$ leading to $r_{3}=r_{4}$.

- Member verification:

The simplified method allowed by Eurocode- 4 is summarized as follows:

Two values for the effective flexural stiffness are distinguished:

$(E I)_{e f f}=E_{a} I_{a}+E_{s} I_{s}+0,6 E_{c m} I_{c}$

$(E I)_{e f f, I I}=0,9\left(E_{a} I_{a}+E_{s} I_{s}+0,5 E_{c m} I_{c}\right)$

where $E_{c m}$ is the concrete modulus of elasticity taking into account the influence of long-term effects, it depends on the values of long and short term loading and the creep coefficient (for reason of simplification, $E_{c m}=E_{c} / 1,6$ in the present work); $I_{a}, I_{s}, I_{c}$ are the respective second moment of inertia of the steel, the rebar and the concrete.

$(E I)_{\text {eff }}$ is used to calculate the elastic critical axial compression force and, subsequently, the relative slenderness whereas $(E I)_{\text {eff }, \text { II }}$ is used to determine the second-order effect of the member.

(1) The resistance of the member under axial compression is verified using:

$$
\frac{N_{E d}}{\chi N_{p l, R d}} \leq 1
$$

where $N_{p l, R d}$ is the plastic compression resistance, calculated with Eq.(5) in which $\theta_{1}=\pi / 2$; $N_{p l, R k}$ is the characteristic value of $N_{p l, R d} ; N_{c r}$ is calculated with Eq.(2) using $(E I)_{e f f} ; \bar{\lambda}$ is calculated using $\bar{\lambda}=\sqrt{N_{p l, R k} / N_{c r}}$. The Eq.(3) provides the reduction factor $\chi$.

(2) The resistance of the member under compression and bending is verified using:

$$
\frac{M_{E d, I I}}{\mu_{d} M_{p l, R d}} \leq \alpha_{M},
$$

where $\mu_{d}$ is provided in Fig.4; $\alpha_{M}=0,9$ for NS and 0,8 for HSS and the second-order bending moment $M_{E d, I I}$ is calculated using:

$$
M_{E d, I I}=\left(M_{E d}+N_{E d} \frac{L}{300}\right) \frac{1}{1-N_{E d} / N_{c r, I I}},
$$

where $N_{c r, I I}$ is calculated using Eq.(2) together with $(E I)_{e f f, I I}$.

- Conditions of use of the simplified method:

To apply the simplified method for circular hollow sections, the following conditions should be satisfied:

- The member is not too slender: $\bar{\lambda} \leq 2,0$;

- The area of rebar shouldn't exceed 6\% of the one of concrete core. 
- The section belongs to Class 3 at the minimum, in order to avoid the local buckling of the steel tube.

\subsubsection{Establishment of optimum problem}

After having the safety condition of columns, we can build up the optimal problem that may be described as the following.

- Cost function and unknowns:

The following parameters may be considered as the variables of the optimal problem:

- The diameter $D$ and thickness $t$ for steel columns;

- The diameter $D$, thickness $t$, distance $b$ (Fig.1), area of rebar, class of concrete and grade of rebar for composite columns.

However, the class of concrete and the grade of rebar are discontinuous quantities with very few practicable values. And thus they are not considered as regular variables of the problem.

Concerning the distance $b$, we can say that, under static loading, the capacity of the section increases if $b$ decreases, with $b$ obviously respecting the constitutive condition. We could therefore fix the value of $b$ at the beginning of the optimum research problem.

Moreover, in order to be able to compare the two solutions, the cost of several quantities (e.g. each grade steel, each grade of rebar and each class of concrete) must be defined taking into account its variability with respect to the time and the country. Since the objective is to draw general conclusions useful for any time and place, a large field of the mentioned costs should be investigated, obviously leading to the complexity of the problem. To avoid this, the following problem for composite columns is considered: two solutions of columns are compared with the same length, the same class of concrete, the same density (\%) of rebar, under the same load, but using two different values of strengths of steel tubes. The variations of length, loads, concrete class, and rebar density will be considered as the parameters (input variable) of the optimum research problem. Therefore, the following cost function is adopted:

$$
C=l\left(A_{a} c_{a}+A_{c s} c_{c s}\right),
$$

where $\mathrm{A}_{\mathrm{cs}}$ is the area of concrete and rebar; $c_{a}, c_{c s}$ are, respectively, the cost per volume of steel and of reinforcement concrete (euros $/ \mathrm{m}^{3}$ ).

Meaning that, when calculating the cost, the concrete and rebars are considered as one single material (reinforced concrete). The parameter $\mathrm{c}_{\mathrm{cs}}$ obviously depends on the class of concrete and the density of rebar.

Finally, two variables have to be examined: the diameter $\mathrm{D}$ and the thickness t. In reality, market catalogues for steel tubes provide discontinuous quantities for the couple $\mathrm{D}$ and $\mathrm{t}$. But, in the present research, in order to generalize the results and simplify the mathematical problem, the diameter $\mathrm{D}$ and the thickness $\mathrm{t}$ are considered as continuous quantities.

\section{- Constraints:}

Using the safety analyses of columns presented in Sections 1 and 2, the constraints for the optimum research problem are summarized as follows:

- Requirement of section classification: Eq.(1);

- Requirement for member buckling resistance: Eq.(4) for steel columns, Eqs.(7) or (8) for composite columns;

- Constitutive condition: $t \leq D / 2$.

- Geometric interpretation of the optimum research problem: 
The optimum research problem can be qualitatively interpreted as it is depicted in Fig.5.

- Mathematical procedure

Mathematically, the problem can be written under the form:

Find $\quad \mathbf{x}=[D, t]$ such that $C(\mathbf{x}) \rightarrow \min$ but $g_{j}(\mathbf{x}) \leq 0, j=1 \div n$,

where $\mathrm{C}(\mathbf{x})$ is the cost function (Eq.(9)); $g_{j}(\mathbf{x})$ are the constraints.

The method of feasible direction is chosen to solve the problem. The explanation of this method is abundantly reviewed in the literature (e.g. [7]). Herein, the main ideas are briefly recalled: (1) an initial point SP is found inside the feasible zoon (Fig.6); (2) a feasible direction $\mathbf{S}$ is established, with which a new point considered as better than the last point (the cost function decreases with the constraints still respected) is found; (3) the allowed distance in the direction $\mathbf{S}$ is limited by a scalar $\alpha^{*}$. The procedure is repeated until an acceptable convergence (optimum) is reached, it is the case when no feasible direction is found.

The $\mathrm{q}^{\text {th }}$ iteration of the process can be written as:

$$
\mathbf{X}^{q}=\mathbf{X}^{q-1}+\alpha^{*} \mathbf{S}^{q}
$$

In the procedure, it is necessary to calculate the gradient of $\mathbf{C}$ and $\mathbf{g}$ although it is sometimes difficult to compute the derivative of these functions such that the gradient is often replaced by the sensitivity:

$$
\frac{\partial \mathbf{g}\left(x_{i}\right)}{\partial x_{i}} \approx \frac{\mathbf{g}\left(x_{i}+\Delta x_{i}\right)-g\left(x_{i}\right)}{\Delta x_{i}}
$$

\subsection{Definition of the index of interest}

At the present time, it seems that the grade of steel S355 is the most popular in construction, it is thus chosen as the reference material. Eq.(9) (with the sub-scripts "355" and "HSS" to distinguish the reference steel and HSS,

$$
\begin{gathered}
C_{355}=l\left(A_{a, 355} C_{a, 355}+A_{c S} c_{c S}\right) ; \\
C_{H S S}=l\left(A_{a, H S S} C_{a, H S S}+A_{c S} c_{c S}\right) ;
\end{gathered}
$$

can be rewritten as

$$
C_{H S S} / C_{355}=\frac{\left(A_{a, H S S} C_{a, H S S} / c_{355}+A_{c s, H S S} C_{c s} / c_{355}\right)}{\left(A_{a, 355}+A_{c s, 355} c_{c s} / c_{355}\right)} .
$$

It is clear that if $C_{H S S} / C_{N S}<1$, then HSS is of interest; on the contrary, if $C_{H S S} / C_{N S}>1$ then NS is of interest; the neutral case occurs if $C_{H S S} / C_{N S}=1$.

\subsection{Field of investigation for simple columns}

In order to draw conclusions that might be true for a lot of practical cases, the following fields are investigated.

- the columns length $l$ varies from 3 to $8 \mathrm{~m}$;

- the compression force $N_{E d}$ varies from 500 to $6000 \mathrm{kN}$; 
- the maximum bending moment $M_{E d \text {, max }}$ to compression force $N_{E d}$ ratio varies from 0 to $0.75 \mathrm{~m}$;

- according to [4], S500, S550, S620 and S690 steels have be considered as HSS (with $\mathrm{f}_{\mathrm{y}}=$ 500, 550, 620 and $690\left(\mathrm{~N} / \mathrm{mm}^{2}\right)$ respectively). In the present work, various steel grades within 500 and 700 are considered. However, in Appendix, in order to limit the number of charts, three supposed HSS steels are examined: S500, S600 and S700; the results concerning an intermediate steel grade could be interpolated using the results of the other steel grades.

- the characteristic value of the compressive concrete cylinder strength varies between $f_{c k}=25 \div 40\left(\mathrm{~N} / \mathrm{mm}^{2}\right)$; the density of rebar varies from $0 \%$ to $6 \%$;

- the cost of HSS to cost of S355 ratio $c_{H S S} / c_{355}=1,1 \div 1,6$. According to [1], these values (interpolated using Fig.1 in [1]) are: $c_{500} / c_{355}=1,138 ; c_{550} / c_{355}=1,260 ; c_{620} / c_{355}=1,340$; $c_{690} / c_{355}=1,382$.

-the cost of reinforced concrete to the cost of S355 ratio $c_{c s} / c_{355}=0,02 \div 0,05$. At the moment, this value in Belgium is around 0,03.

\subsection{Numerical results and comments for simple columns}

In order to illustrate the procedure presented in the above sections, an example is provided here below for a $5 \mathrm{~m}$ length column, submitted to a compression load of $5000 \mathrm{kN}$ and a uniform bending moment of $100 \mathrm{kNm}$. The costs of two columns are compared:

(1) Steel column made of S355 and S690,

(2) Composite column using an outer steel tube made of S355 and S690, with inside concrete C30/37 ( $f_{c k}=30 \mathrm{~N} / \mathrm{mm}^{2}, f_{c d}=20 \mathrm{~N} / \mathrm{mm}^{2}$ ) reinforced with a density of rebar equal to $4 \%$ $\left(f_{s y}=500 \mathrm{~N} / \mathrm{mm}^{2}\right)$.

The summarized results (geometry and costs) are:

(1) For the steel column:

- Optimal solution for column using S355: $\mathrm{D}=49,97 \mathrm{~cm}$; $\mathrm{t}=1,08 \mathrm{~cm}$.

- Optimal solution for column using S690: $\mathrm{D}=33,73 \mathrm{~cm}$; $\mathrm{t}=1,10 \mathrm{~cm}$.

- Comparison of costs:

The ratio $c_{355} A_{355} / c_{690} A_{690}=1,46 c_{355} / c_{690}$, meaning that the use of HSS can provide an economic interest. Let's consider $c_{690} / c_{355}=1,382$ [7], in this case, the economic interest of using $\mathrm{S} 690$ compared to S355 would be 5,6\%.

(2) For the composite column:

- Optimal solution for column using S355: steel tube $\mathrm{D}=40,02 \mathrm{~cm}, \mathrm{t}=0,67 \mathrm{~cm} ; A_{\mathrm{s}}=$ $45,17 \mathrm{~cm}^{2}$ (= $4 \%$ of the concrete area).

- Optimal solution for column using S690: steel tube $D=31,61 \mathrm{~cm}, \mathrm{t}=1,03 \mathrm{~cm} ; A_{s}=$ $26,38 \mathrm{~cm}^{2}$ ( $=4 \%$ of the concrete area).

- Comparison of costs:

Using Eq.(11), one has:

$$
\frac{\text { cost of column using } S 690}{\text { cost of column using } S 355}=\frac{98,95 c_{690} / c_{355}+685,8 c_{c s} / c_{355}}{81,42+1175,1 c_{c s} / c_{355}}
$$


If $c_{690} / c_{355}=1,382$ is adopted again, the use of S690 is of interest if the unrealistic condition

$c_{c s} / c_{355} \geq 1 / 8,8$ is respected. In this case, HSS does not provide any economic interest.

After all calculations achieved in the chosen filed of applications, it is possible to draw several conclusions:

- In many cases, for steel columns, the use of HSS leads to considerable economic profit in comparison with S355 steel. In fact, the use of HSS in case of stocky columns provides the greatest advantage while NS is more economic in case of slender columns. Moreover, the interest of using HSS decreases when the eccentricity increases.

- Depending on the column length and the loading condition $(M / N)$, the charts A1 to A12 in the Appendix show the ratio between the area of HSS columns and the area of NS columns (for simple columns). With these charts, the user can obtain the economic benefit of the use of HSS if the material costs are known. For reason of simplification, only a few charts are presented.

- Even if the relative cost $c_{c s} / c_{355}$ is varying a lot, very few of cases where the use of HSS in composite columns gives economic profit. By way of conclusion, it is not economic to use HSS tubes for composite columns under static loading.

\section{Investigation for columns in frames}

The simple column, studied in Section 2, constitutes a relatively unrealistic case. Indeed, in reality, the columns are connected with other members composing the structure. The pin-end boundary conditions occurring in the case of single columns are rather ideal. While, in the case of columns included in frames, an interaction exists with the rest of the structure, meaning that the main difference between the two cases are the boundary conditions. Figures 7a and 7b are traditionally used to represent the column in braced frames and un-braced frames respectively. Similarly to simple columns, the above described procedure is carried out to compare two solutions of column using NS and HSS.

\subsection{Analysis of columns in frames}

\subsubsection{Effective length}

Traditionally, the concept of effective length has been used to evaluate the stability of columns in frames, using the analogy of the simple column of same length. Wood's research [11] on the effective length is adopted in the present work. According to this, the effective length depends on the stiffness coefficients at column crossings:

$$
\begin{aligned}
& k_{s}=\frac{R_{c}+R_{s}}{R_{c}+R_{s}+R_{b s}} ; \\
& k_{i}=\frac{R_{c}+R_{i}}{R_{c}+R_{i}+R_{b i}} ;
\end{aligned}
$$

where $R_{c}$ is the stiffness of the considered column; $R_{s}$ and $R_{i}$ are the stiffness of the upper and lower columns respectively; $R_{b s}$ and $R_{b i}$ are respectively the sum of the stiffness of all beams connected at the superior node $\mathrm{S}$ and the inferior node I of the considered column (Fig.7).

With $k_{s}$ and $k_{i}$, we can obtain the effective length of the column using the charts that were developed by Wood [11]. However, applying the charts is not very suitable to the automatic computation that is required in the present research, such that the following formulas Eqs.(14) and (15), approximating Wood's charts, are preferred (see [2]). 


$$
\begin{aligned}
& l_{f}=l\left[\frac{1+0,145\left(k_{s}+k_{i}\right)-0,265 k_{i} k_{s}}{2-0,364\left(k_{s}+k_{i}\right)-0,247 k_{i} k_{s}}\right] \text { for braced columns } \\
& l_{f}=l\left[\frac{1-0,37\left(k_{s}+k_{i}\right)+0,01 k_{i} k_{s}}{1-0,9\left(k_{s}+k_{i}\right)+0,8 k_{i} k_{s}}\right]^{1 / 2} \text { for un-braced columns }
\end{aligned}
$$

As soon as the effective length is known, the stability analysis of columns in frames is similar to the one of single columns.

\subsubsection{Horizontal displacement of column in un-braced frames}

The stiffness of columns made of HSS is smaller than the one of columns made of NS, such that the horizontal displacement might become important. Taking into account the displacement in the optimal problem for columns in un-braced frames is necessary in order to have realistic results. The horizontal displacement of the column in un-braced frames due to the horizontal load (Fig.7) is calculated using the following formula [8]

$$
\Delta=\frac{P_{k} l^{3}}{12 E I_{c}}\left(1+\frac{3\left(k_{i}+k_{s}-k_{i} k_{s}\right)}{4-3 k_{i}-3 k_{s}+2 k_{i} k_{s}}\right),
$$

where $E$ is the modulus of plasticity for steel/composite column; $P_{k}$ is the characteristic value of the horizontal load (Fig.8).

If the second-order effects are taken into account, the displacement becomes

$$
\Delta=\frac{P_{k} l^{3}}{12 E I_{c}}\left(1+\frac{3\left(k_{i}+k_{s}-k_{i} k_{s}\right)}{4-3 k_{i}-3 k_{s}+2 k_{i} k_{s}}\right)\left(\frac{1}{1-N_{E k} / N_{c r}}\right),
$$

with $N_{k}$ is the characteristic value of the vertical load (Fig.8).

\subsection{Optimum problem for columns in frames}

If columns in braced frames, the optimum problem is similar to the one if simple columns. A procedure for calculating the effective length using Eqs.(14) and (15) is simply added. The load combination shown on Fig.8a is used for the stability study, achieved using Eqs.(4), (7) and (8).

If columns in un-braced frames, besides this new procedure, the horizontal displacement has to be limited. In general, the limit for displacements depends on each project and with the agreement of the client. In this work, the value of $l / 250$ is used as the limitation of the horizontal displacement of the columns, where $l$ is the column length. For that case, the load combination reported on Fig.8b is adopted and must respect the displacement condition written as

$$
\Delta=\frac{P_{k} l^{3}}{12 E I_{c}}\left(1+\frac{3\left(k_{i}+k_{s}-k_{i} k_{s}\right)}{4-3 k_{i}-3 k_{s}+2 k_{i} k_{s}}\right)\left(\frac{1}{1-N_{E k} / N_{c r}}\right) \leq l / 250 .
$$

For the columns in un-braced frames, the equivalent uniform moment factor $C_{m}=1$ should be adopted since the extremities of the column are the critical parts to be considered in the stability problem (Fig.9). In this case, it is not necessary to verify the cross-sections strength condition.

Moreover, it is worth noting that, if the effective length is calculated using the mentioned equations (14) and (15), the P- $\Delta$ effect is taken into account. And therefore, the bending moment $M_{E d \text {, max }}$ (Fig.8a) should be calculated using the first order theory. 


\subsection{Field of investigation for columns in frames}

For the two types of column shown in Fig.7, the field of investigation of the simple column (Section 2.3) is reused. Additionally, the variation of the coefficients $k_{i}$ and $k_{s}$ and of the horizontal load have to be taken into account. Besides, the characteristic value of the axial load has to be considered (Fig.8b). In order to be able to compare two solutions of columns (using HSS and NS) and decrease the complexity of the problem, the following assumptions are made:

- The stiffness at the bottom and top ends of the column are the same $R_{s}=R_{i}=R_{c}$;

- The same configuration of beams is used in every case: $R_{b s}=R_{b i}=R_{b}$.

The equations (12) and (13) become:

$$
k_{s}=k_{i}=k=\frac{2 R_{c}}{2 R_{c}+R_{b}},
$$

in which $\mathrm{k}$ varies from 0 to 1 .

- The characteristic value of the vertical load is approximated as $N_{E k}=N_{E d} / 1,4$;

- The ratio $P_{k} / N_{E k}$ varies from $1 / 250$ to $1 / 2$. This can be explained by the fact that if one considers a frame of $n_{s}$ stories and $n_{b}$ bays as the one shown in Fig.10. Prior to any calculation, the approximately estimations of the vertical load and the horizontal load acting on the considered column are:

$$
\begin{aligned}
& N=n_{s} p \frac{B_{1 A}+B_{1 B}}{2} \frac{B_{2 A}+B_{2 B}}{2} ; \\
& P=w \frac{B_{1 A}+B_{1 B}}{2} n_{s} h \frac{1}{n_{b}} .
\end{aligned}
$$

Consequently, one has:

$$
P / N=\frac{w}{p} \frac{h}{n_{b}\left(\frac{B_{2 A}+B_{2 B}}{2}\right)} .
$$

In traditional buildings, the following limitations are used (units are $\mathrm{kN}$ and $\mathrm{m}$ ): $10 \leq w \leq 20$; $50 \leq p \leq 120 ; 2 \leq n_{b} \leq 8 ; 3 \leq h \leq 5 ; 6 \leq B_{2 A}+B_{2 B} \leq 16$. These limitations introduced in Eq.(17) provide us with the suggested upper and lower bounds.

\subsection{Comparison procedure for columns in frames}

The same system of beams is supposed to be used for the two cases of column, meaning that we consider a given set of beams and want to compare the optimal NS and HSS columns in this building.

Nevertheless, the stiffness of the columns is not the same leading to different coefficient $k$. If $k$ 's value is chosen for one column type, it is an unknown for the other column type. Therefore, the following procedure is adopted to solve the problem: 
Step 1: Assign a value to $k$ (the values varies from 0 to 1 with a step of 0,1 ) and calculate the effective length according to Eqs.(14) and (15), the column is now considered as a simple column.

Step 2: Achieve the optimum research problem (Section 3.2) for the column made of steel S355.

Step 3: Calculate $R_{c}$ for this optimal column section.

Step 4: Determine the value of $R_{b}$ using Eq.(16) and the previously calculated $k$ and $R_{c}$.

Step 5: This value of $R_{b}$ is considered as an input of the optimum research problem for HSS column. It is worth pointing that $R_{c}$ and $k$ are, of course, updated during the procedure such that Eq.(16) is satisfied.

Step 6: The comparison of the two types of column can be made (Section 2.2).

\subsection{Numerical results and comments for columns in frames}

In order to clarify the comparison procedure, an example is presented in details: Let's consider a column in an un-braced frame with a length of $l=4 \mathrm{~m}$, submitted to $N_{E d}=2000 \mathrm{kN}$ and $P_{k}=33 \mathrm{kN}$ (see Fig.8). One compares the price of two columns made of S355 and S690 grades.

Step 1: Let consider $\mathrm{k}=0.2$ for instance, the effective length is calculated using Eq.(15): $l_{f}=450,5 \mathrm{~cm}$.

Step 2: The optimum research problem is solved for a column made of S355: $D_{o p, 355}=36,14 \mathrm{~cm} ; t_{o p, 355}=0,78 \mathrm{~cm} ; A_{355}=86,65 \mathrm{~cm}^{2}$; the elastic buckling load $N_{c r, 355}=13480 \mathrm{kN}$; the stiffness $R_{c, 355}=8108 \mathrm{kNm} ; \quad N_{E d} / N_{c r, 355}=6,92$ (sway column) and the relative horizontal displacement $\Delta / l=1 / 418$.

Step 3: With the optimal section: $R_{c}=7113,15 \mathrm{kNm}$.

Step 4: The stiffness of the contiguous beams is calculated using Eq.(16): $R_{b}=56918 \mathrm{kNm}$.

Step 5: Then, the optimum research problem is solved for a column made of S690 and characterized by the same configuration of beams $\left(R_{b}=64862 \mathrm{kNm}\right): D_{o p, 690}=28,60 \mathrm{~cm}$; $t_{o p, 690}=0,93 \mathrm{~cm} ; A_{690}=81,10 \mathrm{~cm}^{2}$; the elastic buckling load $N_{c r, 690}=8725 \mathrm{KN}$; the stiffness $R_{c, 690}=4077 \mathrm{kNm}$; the coefficient $\quad k_{690}=0,125$; the effective length $l_{f, 690}=430 \mathrm{~cm} ; N_{E d} / N_{c r, 690}=4,36$ (sway column) and the relative displacement $\Delta / l=1 / 250$.

Step 6: Comparison: one has $c_{355} A_{355} / c_{690} A_{690}=1,07 c_{355} / c_{690}$ thus the use of $\mathrm{S} 690$ is of interest if $c_{690} / c_{355} \leq 1,16$. Although this conclusion depends on the market price, we can say that there are very few possibilities where S690 is interesting in this case.

A large number of cases covering the field of investigation (Section 3.3) are computed. For reason of clarity, only a limited amount of charts are chosen to show the volume reduction of HSS columns in comparison with NS columns are reported in the Appendix. Generally, the following comments and conclusions can be drawn:

- If braced frames and steel columns, the domain of interest of HSS (positive economic profit) is greater than the one for simple columns. This can be explained by the fact that the simple column effective lengths (being the column length) are the same for NS and HSS columns. On the contrary, the effective length of the column in braced frames (with the same beam system) is smaller if HSS is used instead of NS. Even if the bending moments in braced frame are not significant in practice but different values of the eccentricity are considered in the present work. 
- The economic benefit of the use of HSS in un-braced frames is smaller than the one in the case of braced frames. The displacement condition is responsible of this, emphasizing the disadvantage of the use of HSS. The volume reductions are also shown in the Appendix.

- Generally, the terms sway (if the vertical to elastic critical load ratio $N_{E d} / N_{c r}<10$ ) and non-sway frames are used for frames. It is not convenient to use this kind of classification for a comparison of the economic interest, but because these terms are widely used, the following comment has been drawn looking at the numerical results: there is no benefit in using HSS in sway frames with $N_{E d} / N_{c r}<10$ for a comparison made on the basis of frames using S355 steel.

- As it is the case for single columns, there are very few possibilities of composite columns for which the use HSS tubes provide an economic profit.

\section{Investigation for frames}

To design a frame, the following quantities are necessary: vertical loads, horizontal loads, frame configuration (number of stories, number of span, height of stories...) and technology conditions, etc. It seems unfeasible to consider a certain amount of frames by varying the mentioned quantities and cover almost all practical possibilities. Therefore, even if the optimum design problem could be defined (taking into account the strength, stability and stiffness conditions) and solved using appropriate computational software, the resulting charts wouldn't be similar to the ones obtained in the case of isolated columns.

Nonetheless, the comments of Section 3.4 are also useful for frames. It is the reason why two simplified procedures are proposed here below to help decision-making regarding the steel grade, before any detailed design of the frame be carried out.

The first one: This method consists of the following steps: Firstly, prior to any computation, the engineer's expertise leads him to first choose the member sizes of the frame. Afterwards, a global analysis of the frame is introduced in two cases: (1) the first case aim to find the critical internal forces in the columns (design values); (2) in second case we apply only horizontal load with characteristic value to obtain this kind of load distributing in each column. Finally, with the mentioned internal forces and horizontal loads, using the charts provided in the Appendix we could assess the economic interest of the use of HSS.

The second one: In this method, we consider each floor separately and choose a column to be considered as the representative column. It is worth choosing an average column instead of the overloaded one. The procedure is summarized in three steps: (1) firstly, the vertical load and horizontal load are calculated for the considered floor; (2) next, the loads acting on the representative column are determined, for that purpose the total loads acting on the floor is divided by the number of columns; (3) the charts provided in the Appendix could be used to assess the economic interest of the use of HSS. This method is more straightforward but less accurate than the first one.

\section{Conclusion}

The economic interest of the use of HSS circular tubes in steel and composite columns submitted to static loading is investigated in the present research paper. The general idea is to compare the costs of columns made of HSS and NS. In order to find comparable designs in each category, the optimum research problem is defined such that the cost of the column is minimum. The realist aspect of the results is confirmed using the current Eurocodes [3, 4, 5] rules for checking the safety of the structures. From simple columns to columns in braced and un-braced frames are considered. A large field of investigation covering almost all possibilities is examined by an automatic algorithm leading to rather general conclusions.

For each investigated case, several charts are provided depending on the loading condition $\mathrm{M} / \mathrm{N}$. In one chart, depicting the length to compression load curves, the user is able to determine the required area of HSS to required area of NS ratio for his column. And depending on the material 
cost of the market, the user can define the domain of interest of the use of HSS. For reason of simplification, only a few charts are presented in Appendix. And for whole frames, tracks are provided to help decision-making process.

It is worth pointing out several conclusions for steel simple columns: (1) in many case, the use of HSS leads to considerable economic profit in comparison with S355 steel, especially in case of stocky columns for which the greatest advantage is observed; (2) the interest of using HSS decreases when the eccentricity increases.

And for steel columns in frames: (1) the domain of interest of the use of HSS in braced frames is thought to be relatively large; (2) the economic benefit of the use of HSS in un-braced frames is smaller than the one in the case of braced frames, the displacement condition is responsible of this, emphasizing the disadvantage of the use of HSS; (3) generally, there is no benefit in using HSS in sway frames compared to frames using S355 steel.

In any case (isolated column or columns in frames), even if the relative cost $c_{c s} / c_{355}$ is varying a lot, there are very few possibilities of composite columns for which the use HSS tubes provide an economic profit.

Finally, the methodology is thought to be applicable for other problems, such other section shapes for instance (e.g. I/H shape). 


\section{Appendix}

In this appendix, the charts show the volume reduction of HSS (S500, S600, S700) in comparison with S355, in other words: $A_{H S S} / A_{N S}$. The horizontal axis represents the column lengths $(\mathrm{m})$ and the vertical axis provides the compression load $(\mathrm{t})$. The title of each chart informs the user about: $M_{E d} / N_{E d}$ (replaced by $\mathrm{M} / \mathrm{N}$ ) and $P_{k} / N_{E k}$ (replaced by $\mathrm{P} / \mathrm{N}$, for reason of clarity).

The charts are arranged in the following order:

- Figs. A1 - A12 for simple columns;

- Figs. A13 - A24 for columns in braced frames, with $k=0,3$;

- Figs. A25 - A72 for columns in un-braced frames, with $k=0$.

The domain where the economic profit could be expected is always represented by the group of lines in cold colours.

The user can also interpolate the results for its own convenience or may request the authors for more information.

\section{Acknowledgements}

This work was carried out with a financial grant from the Research Fund for Coal and Steel of the European Community, within ATTEL project: "Performance-Based Approaches for High Strength Steel Tubular Columns and Connections under Earthquake and Fire Loadings”, Grant $\mathrm{N}^{0}$ RFSR-CT-2008-00037.

\section{References}

[1]. Corbett KT, Bowen RR and Petersen CW. High strength steel Pipeline Economics. Proceeding of The Thirteenth International Offshore and Polar Engineering Conference. Honolulu, Hawaii, USA, May 2003.

[2]. De Saxce G, Nguyen DH. Pour une formulation unifiée du problème d'analyse et le problème d’instabilité par flambage des barres. Internal report, University of Liege, 1984.

[3]. Eurocode 3: Design of steel structures - Part 1-1: General rules and rules for buildings. CEN2005.

[4]. Eurocode 3: Design of steel structures - Part 1-12: Additional rules for the extension of EN 1993 up to steel grades S700. CEN-2007.

[5]. Eurocode 4: Design of composite steel and concrete structures, Part 1-1: General rules and rules for buildings. CEN-2005.

[6]. Galambos TV, Hajjar JF, Earls CJ. Required Properties of High-Performance Steels. NISTIR 6004, National Institute of Standard and Technology, USA 1997.

[7]. Johansson B, Collin P. Eurocode for high strength steel and application in construction. Lulea University of technology - Sweden, 2006.

[8]. Massonnet Ch, Save M. Calcul plastique des constructions, Volume 1. Edition NELISSEN, Belgium, 1976.

[9]. Veljkovic M, Johansson B. Design of hybrid steel girders. Journal of Constructional Steel Research, 2004 (60): 535-547.

[10]. Venderplaats GN. Numerical optimization techniques for engineering design: with applications. McGraw-Hill, 1984. 
[11]. Wood RH. Effective lengths of columns in multi-storey buildings. The Structural Engineer, $\mathrm{N}^{\mathrm{0}}$, Vol 52, 1974.

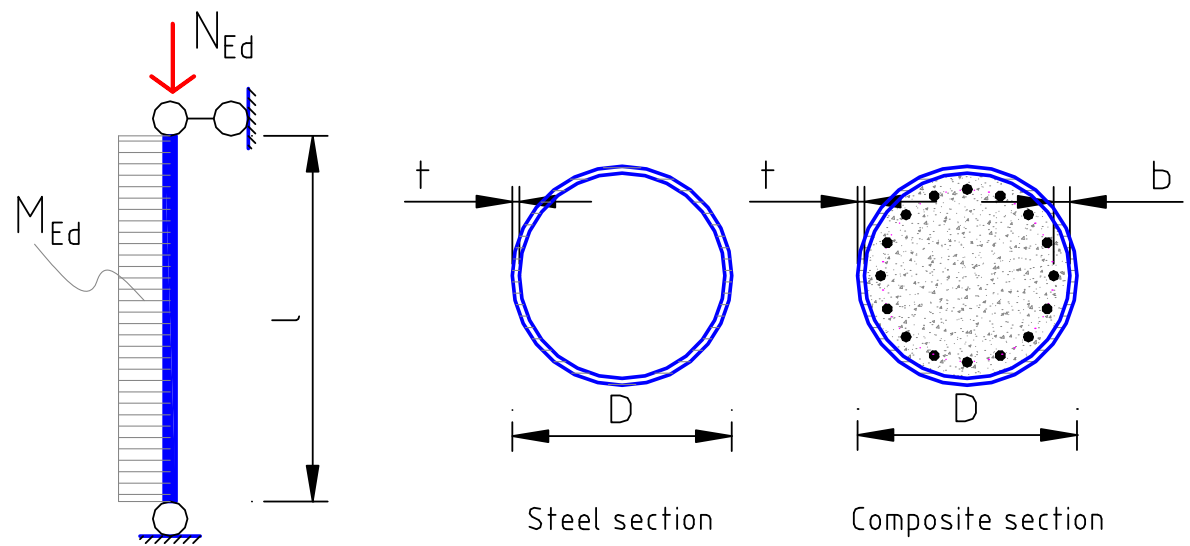

Fig.1. Single column

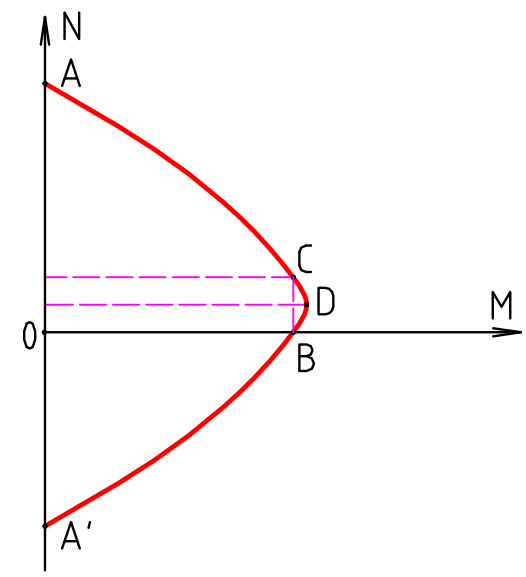

Fig.2: Interaction curve for circular composite section 

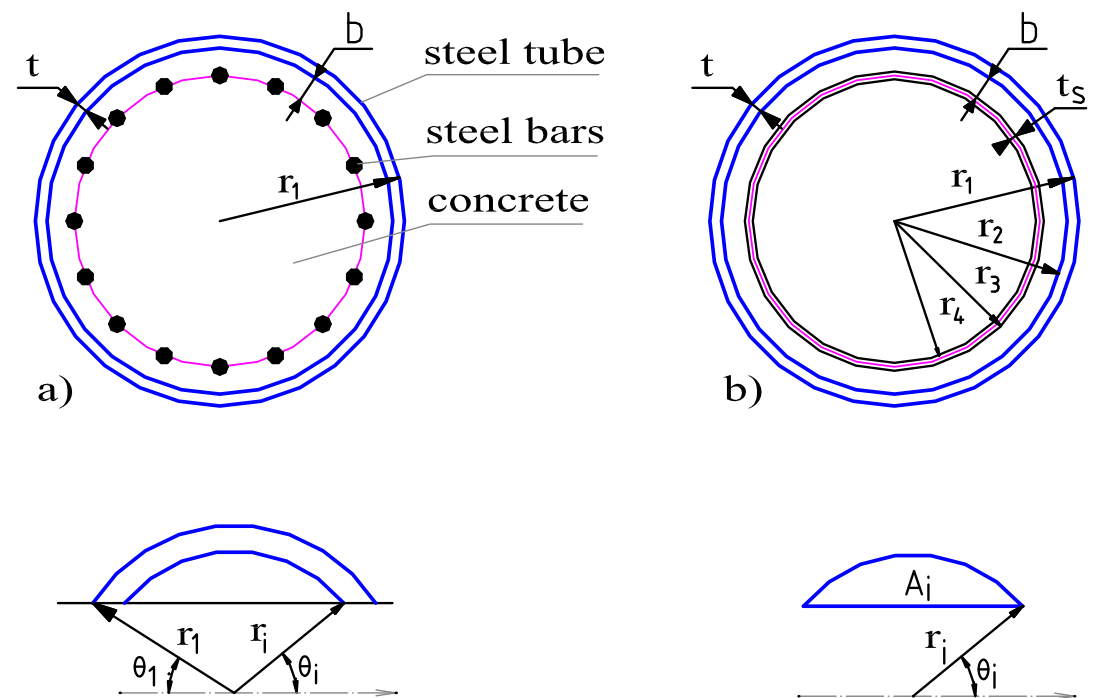

c)

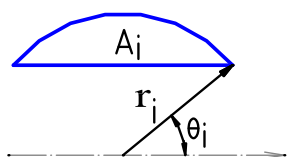

d)
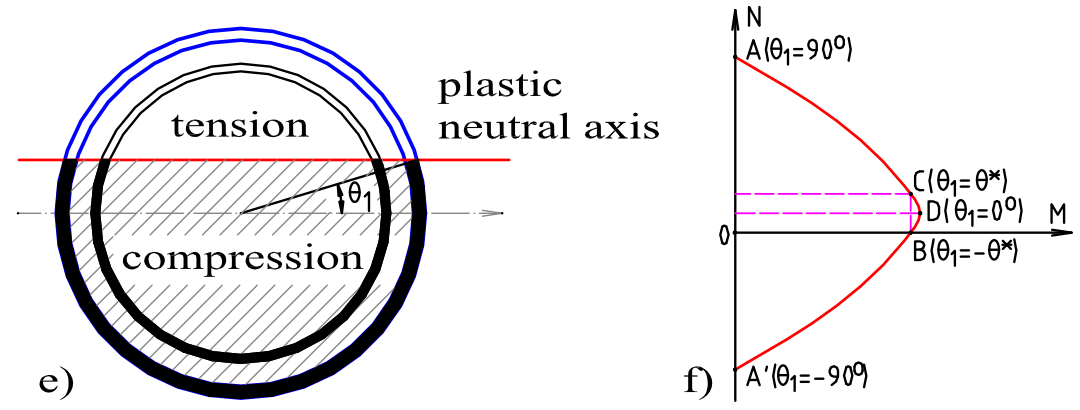

Fig.3: Analysis of composite section

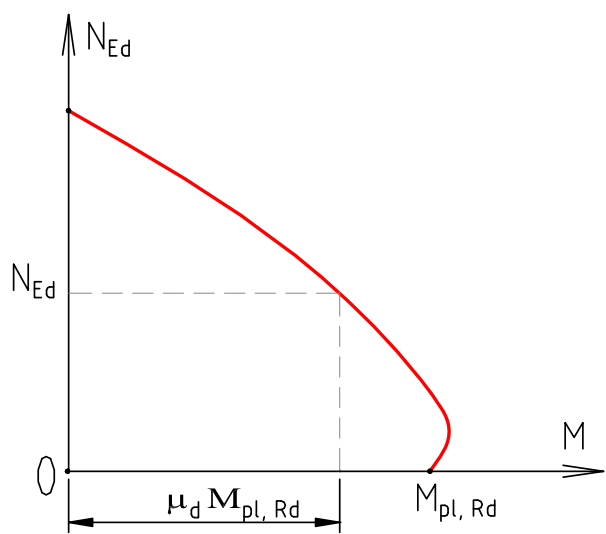

Fig.4: Member verification for composite columns

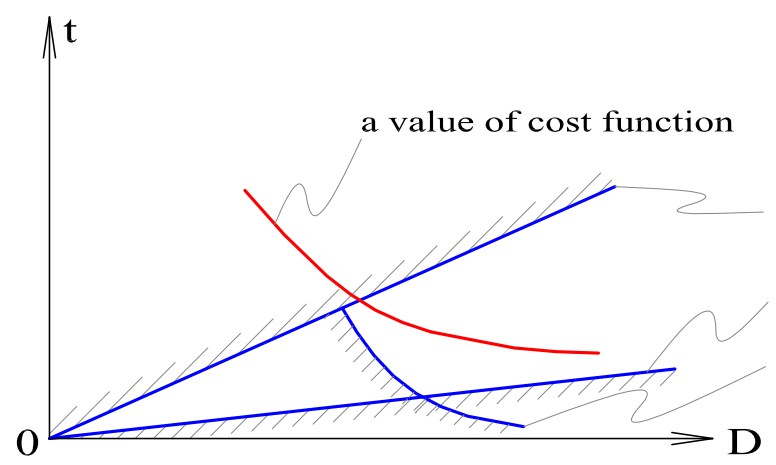

constitutive condition requirement of section class requirement for member buckling

Fig.5: Geometric interpretation of the optimum research problem for simple columns 


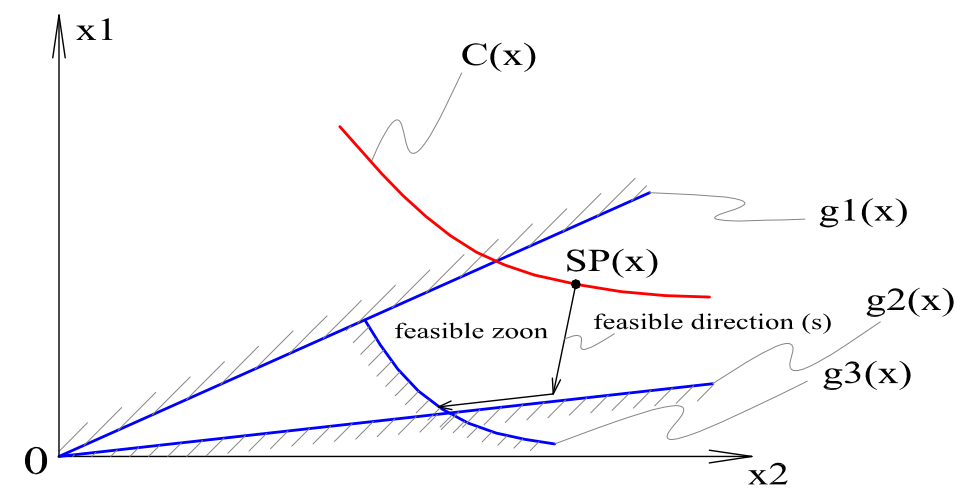

Fig.6: Illustration of the optimum research problem procedure

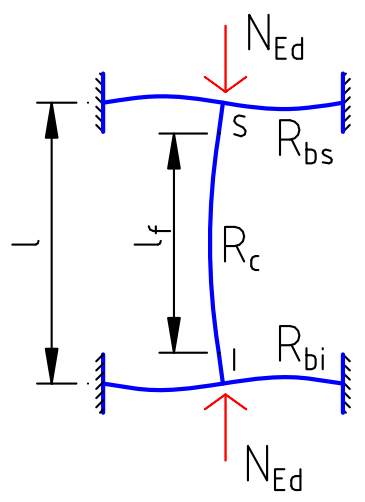

a) column in braced frames

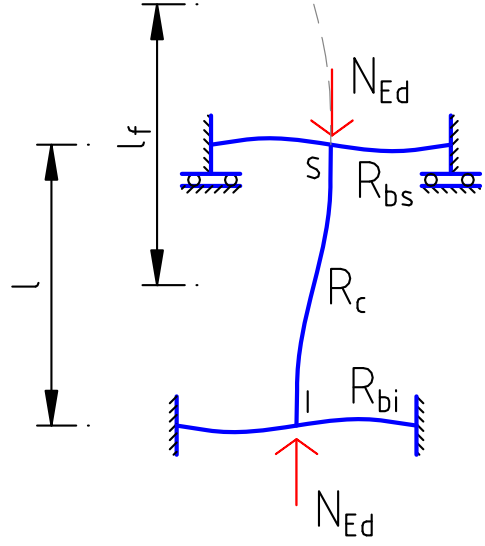

b) column in un-braced frames

Fig.7. Column in frames

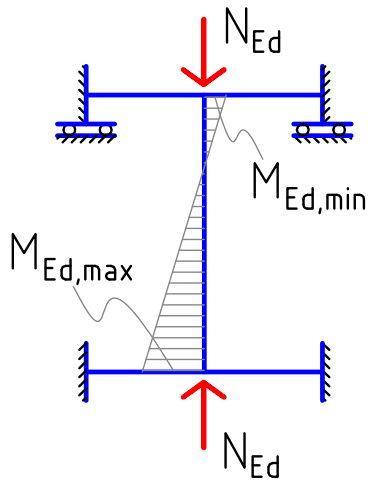

a) Ultimate state

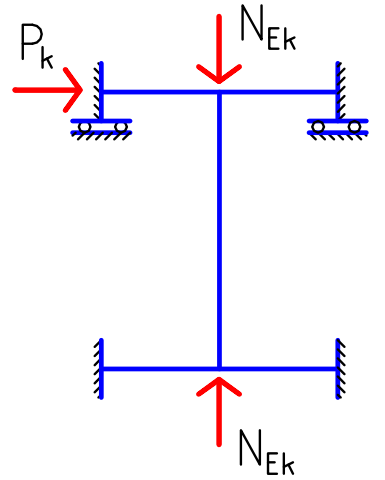

b) Serviceability limit state

Fig.8. Two states to be verified for column in un-braced frames 

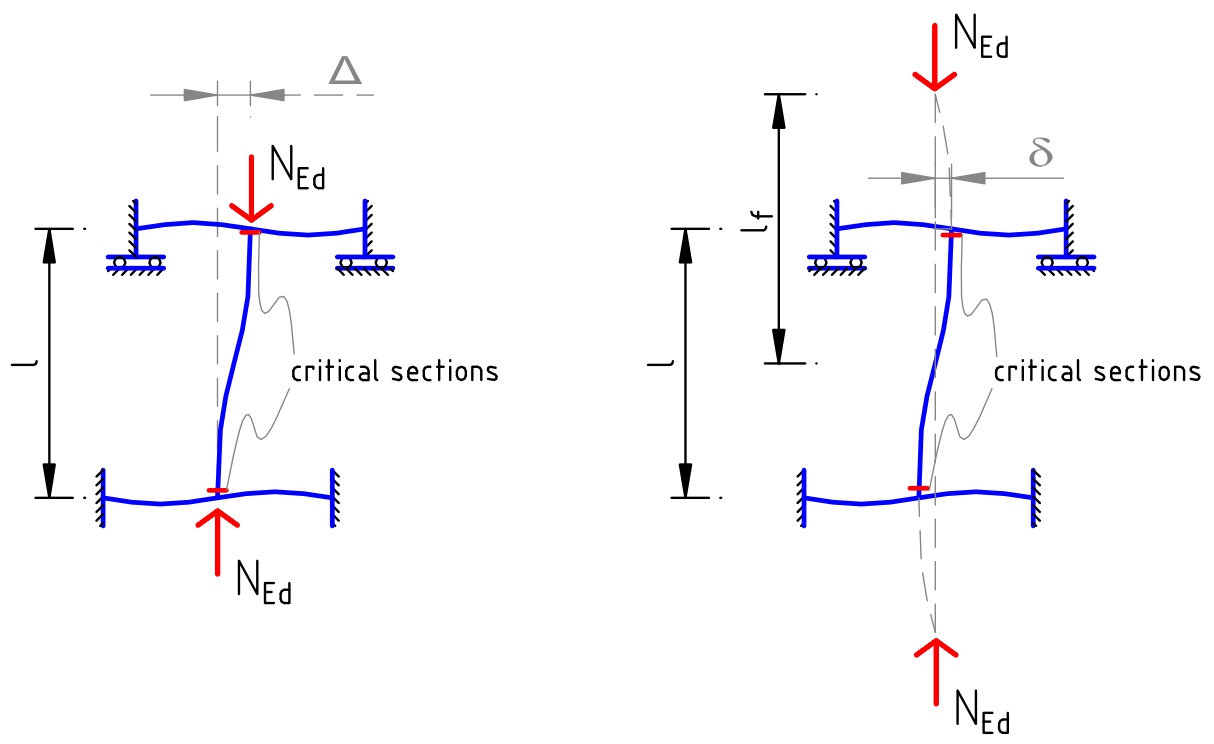

Fig.9. Critical sections for columns in un-braced frames

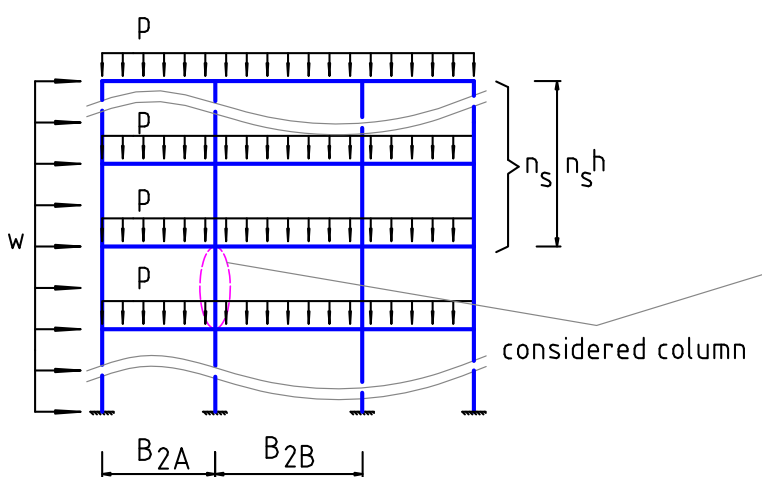

considered frame

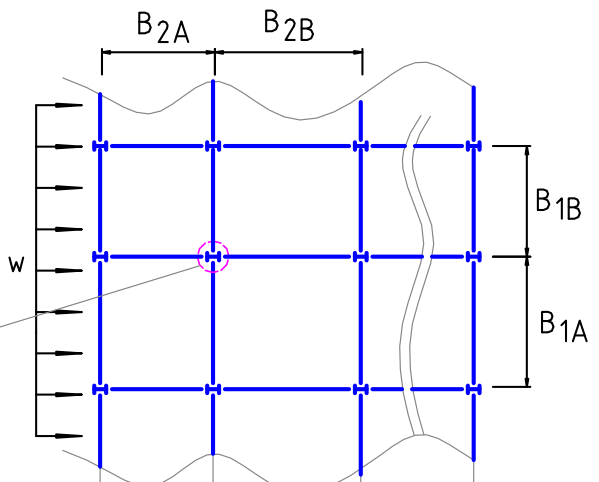

(1) (2)

Fig.10. Evaluation of the loads acting on columns 
Charts 1 to 12. Single columns

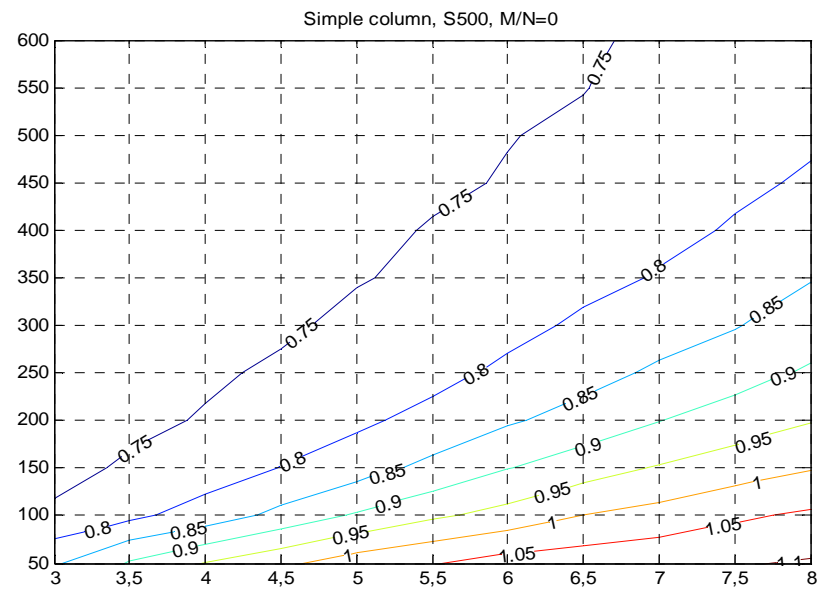

Fig.A1

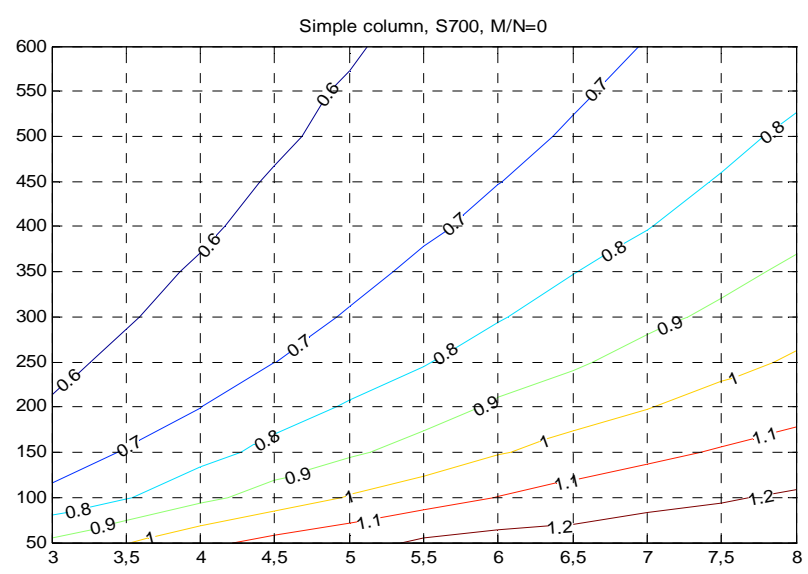

Fig.A3

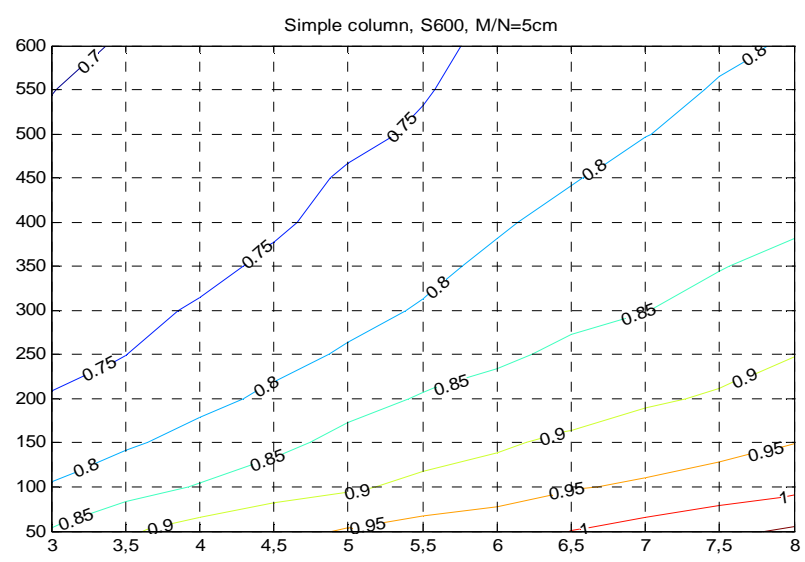

Fig.A5

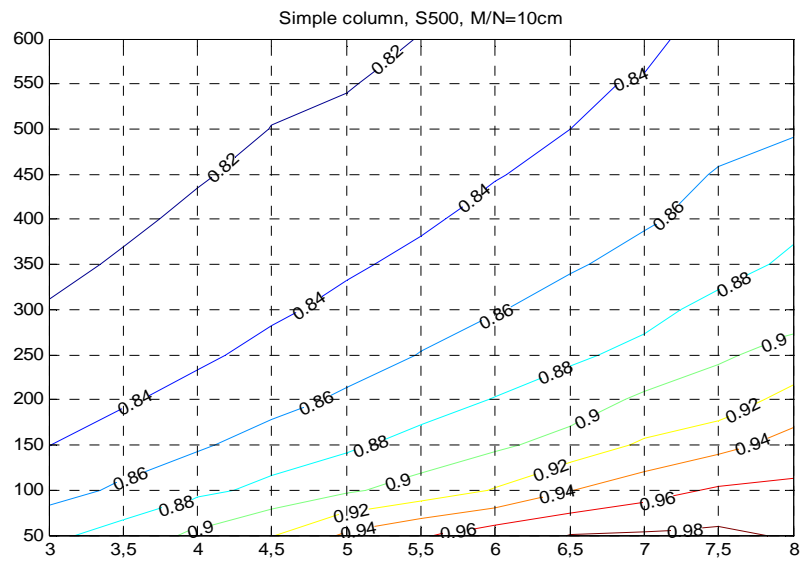

Fig.A7

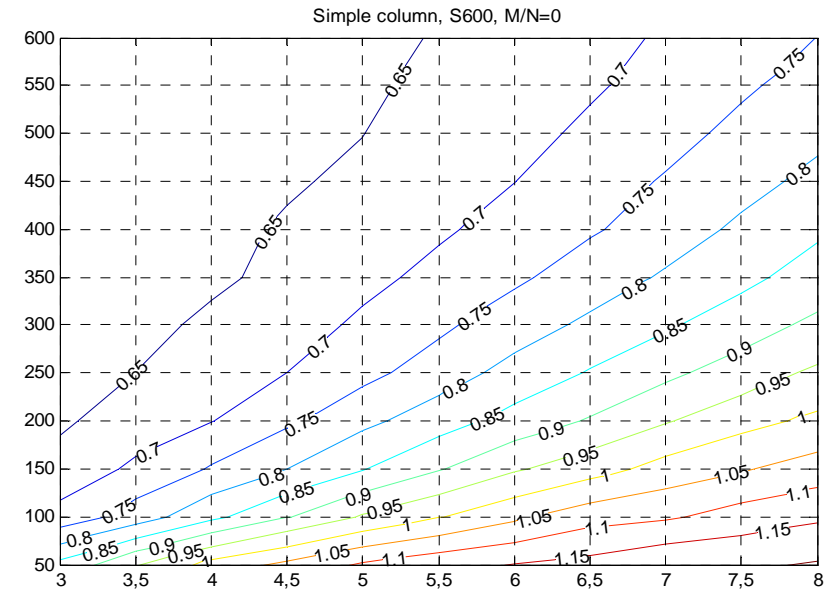

Fig.A2

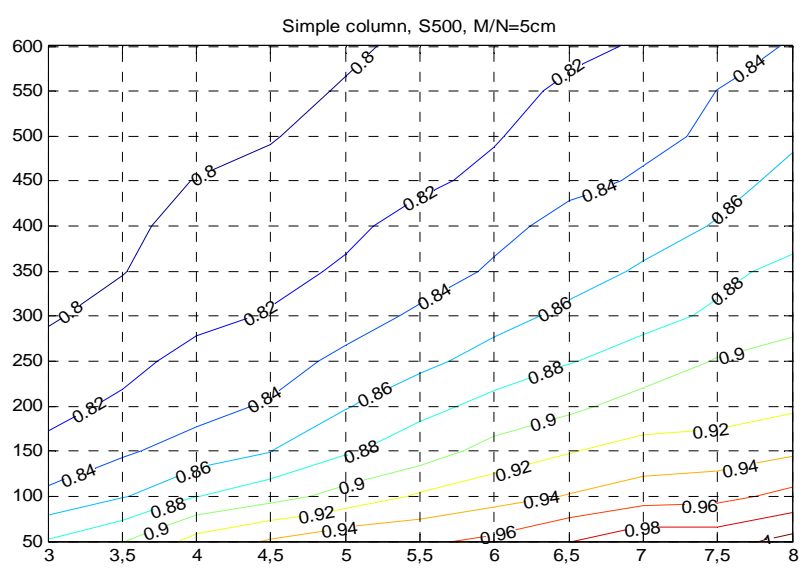

Fig.A4

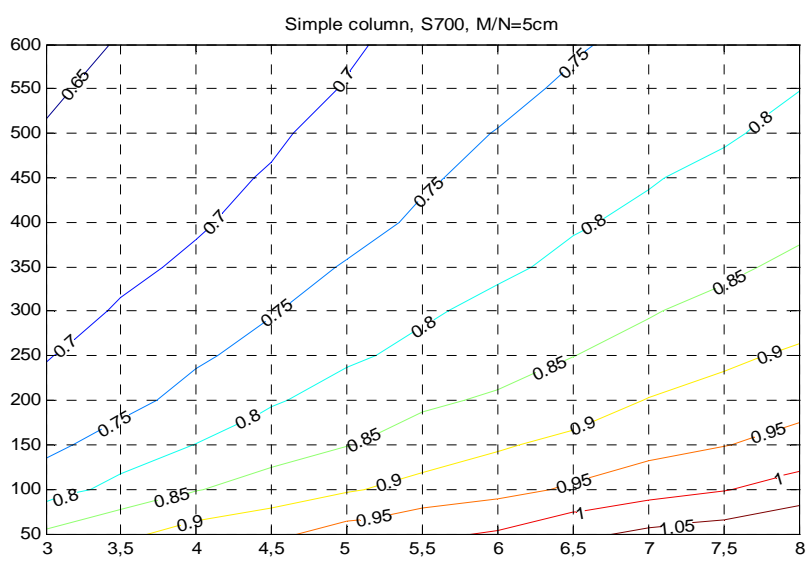

Fig.A6

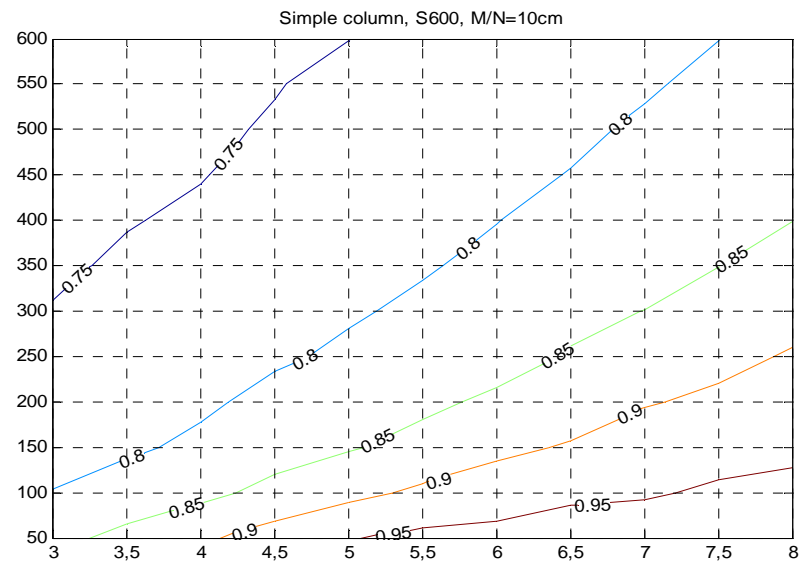

Fig.A8 


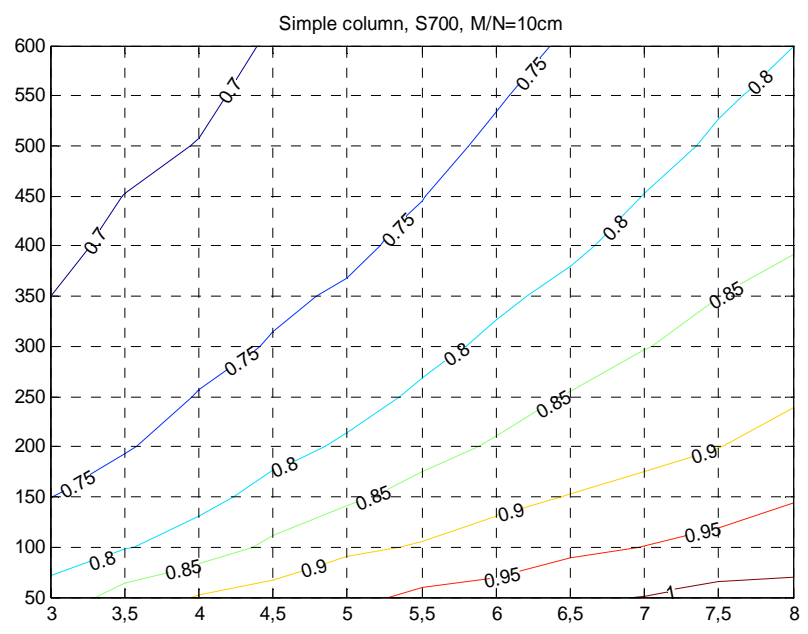

Fig.A9

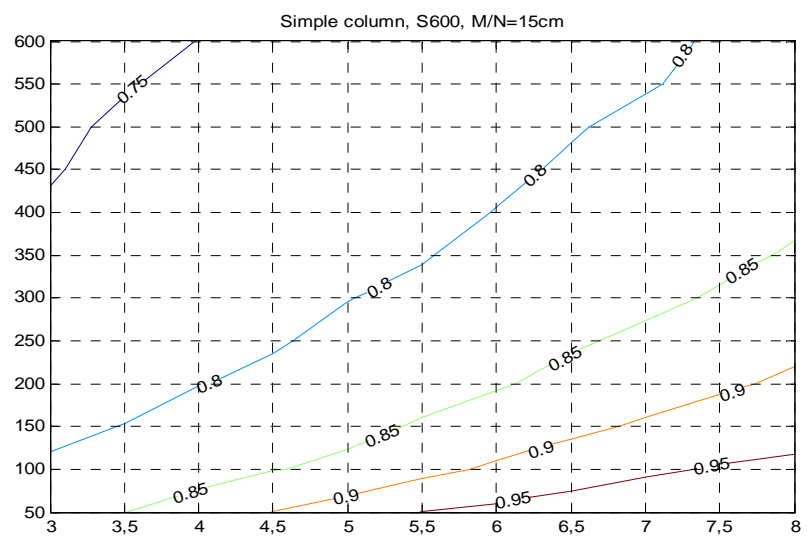

Fig.A11

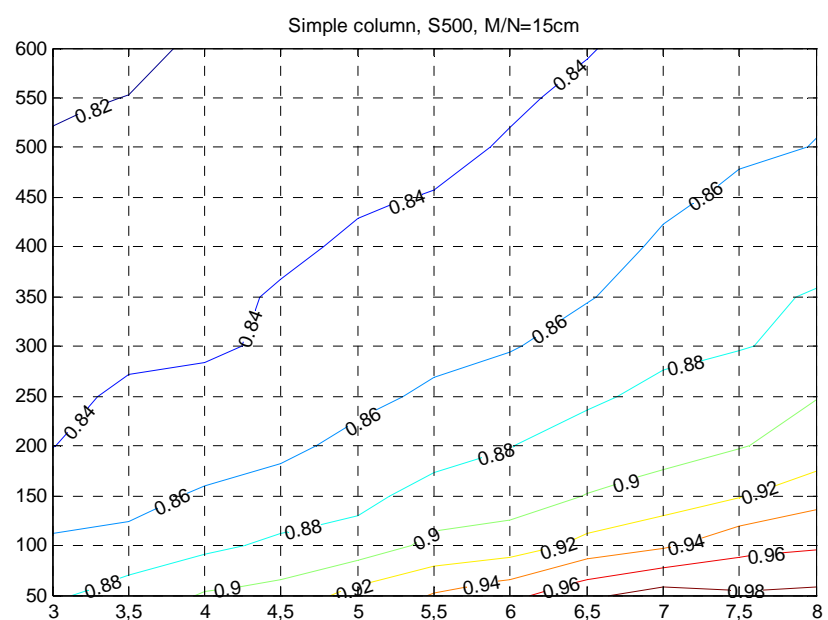

Fig.A10

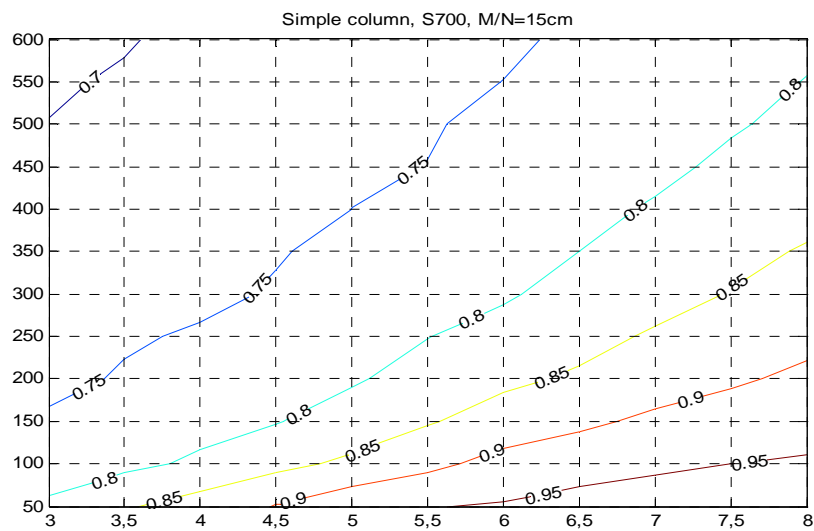

Fig.A12

Charts 13 to 24. Columns in braced frames

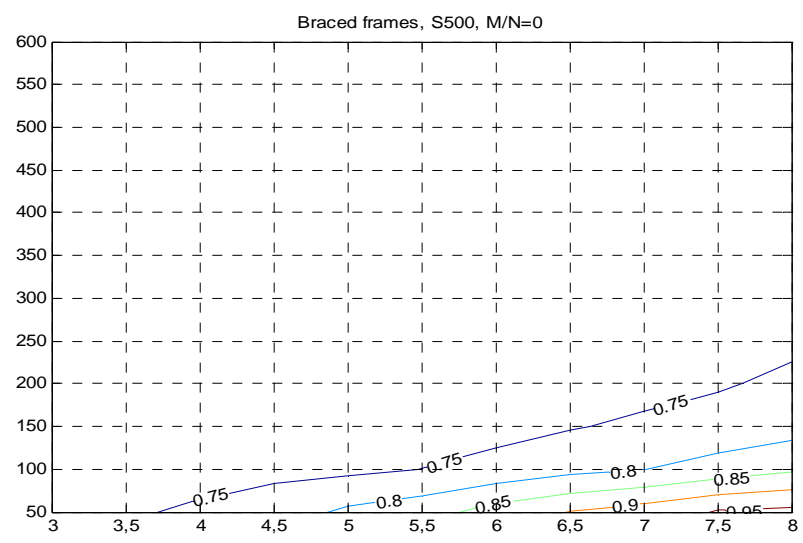

Fig.A13

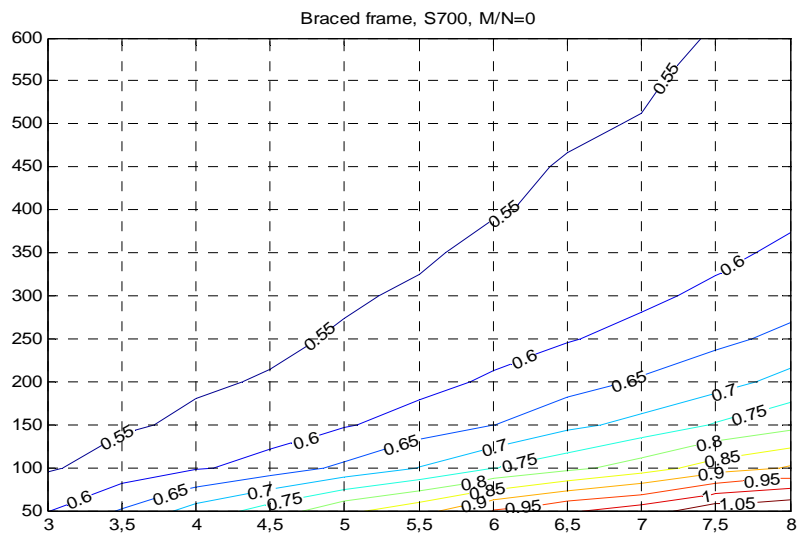

Fig.A15

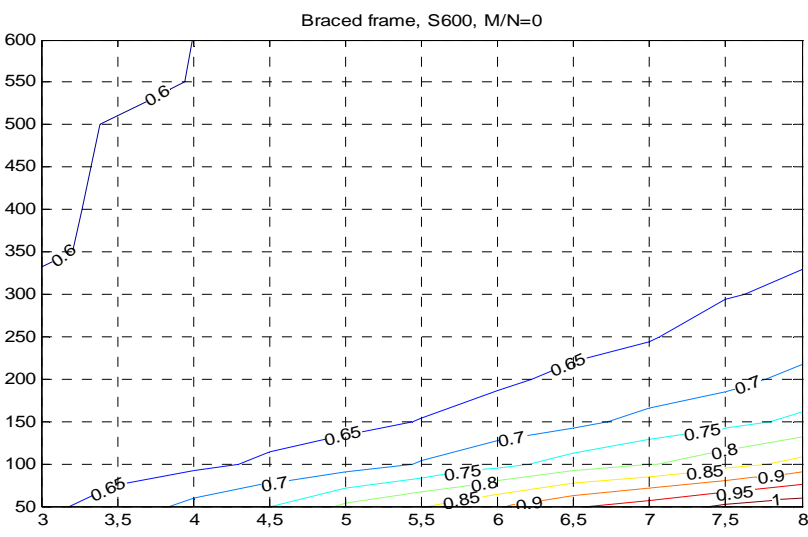

Fig.A14

Braced frame, $\mathrm{S} 500, \mathrm{M} / \mathrm{N}=5 \mathrm{~cm}$

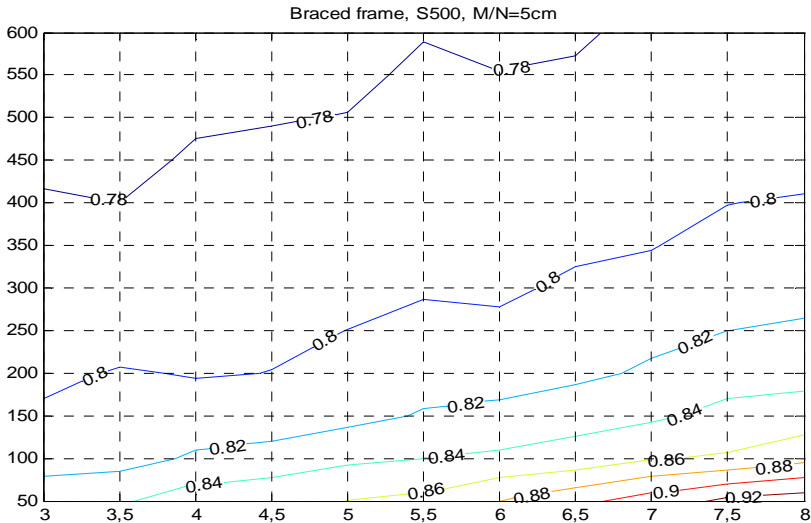

Fig.A16 


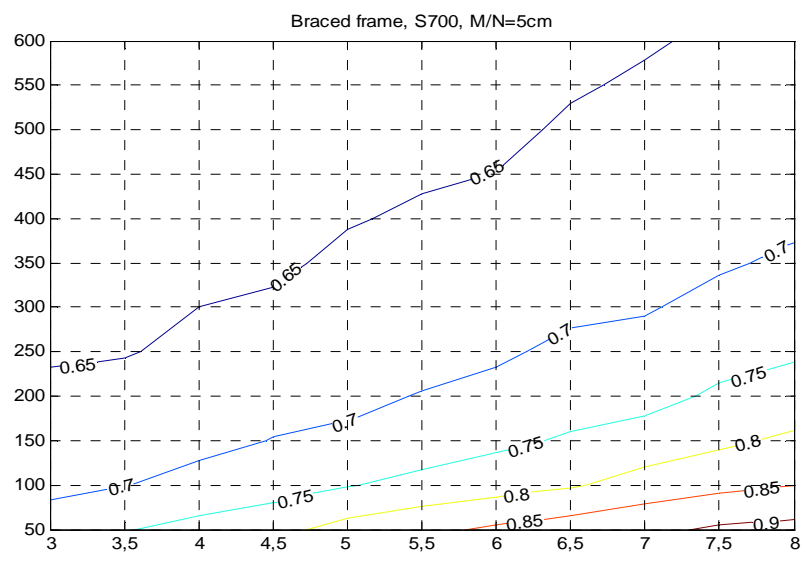

Fig.A17

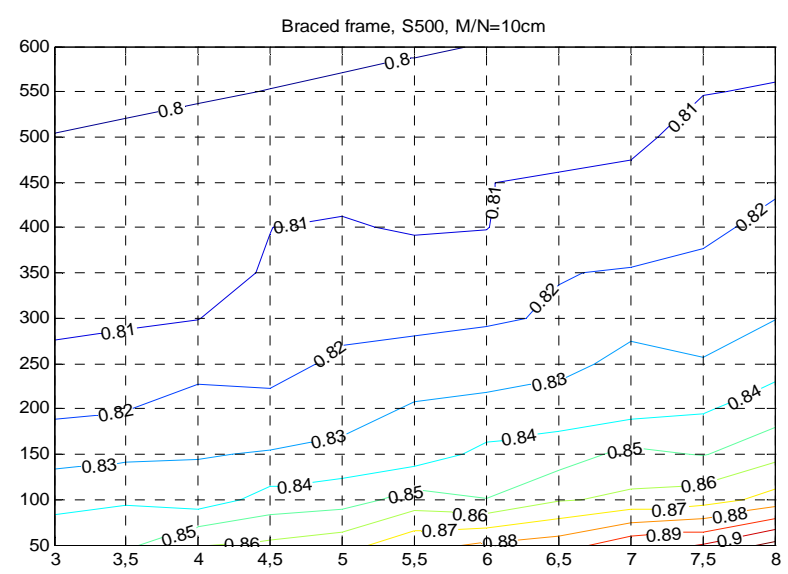

Fig.A19

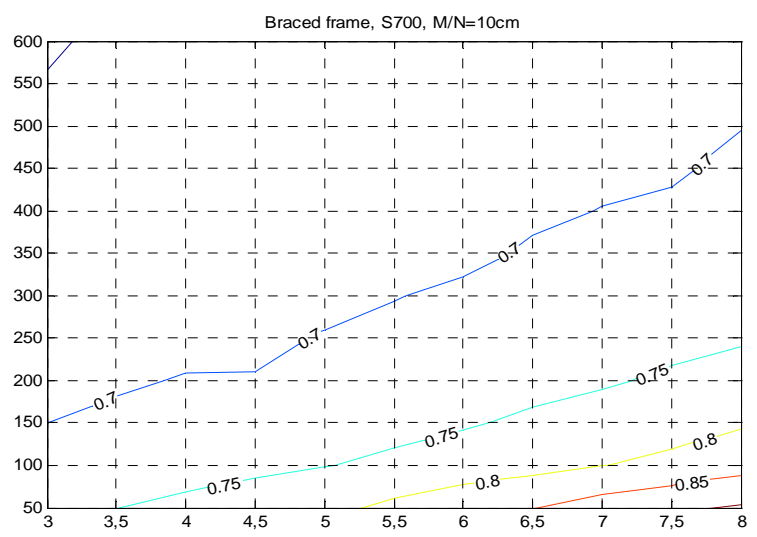

Fig.A21

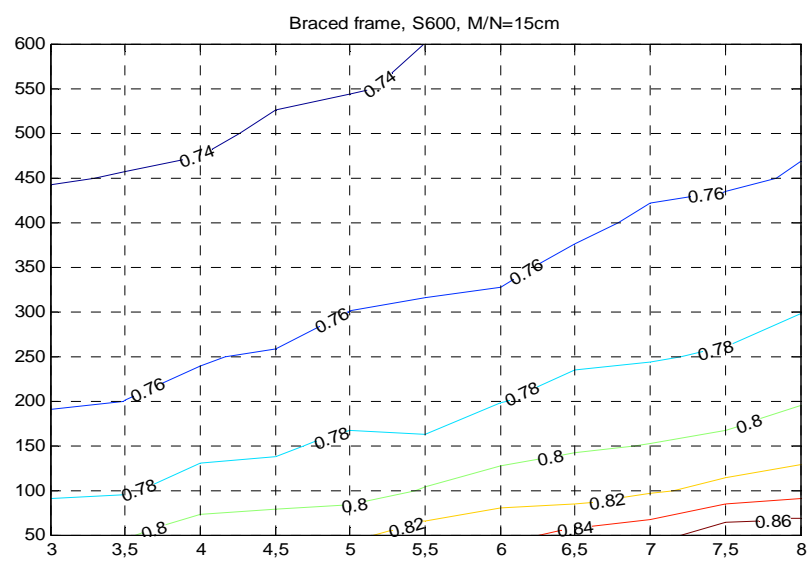

Fig.A23

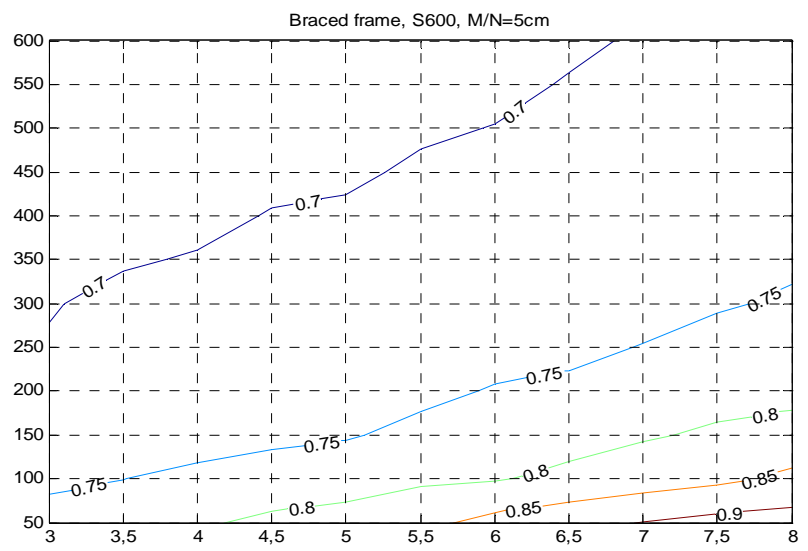

Fig.A18

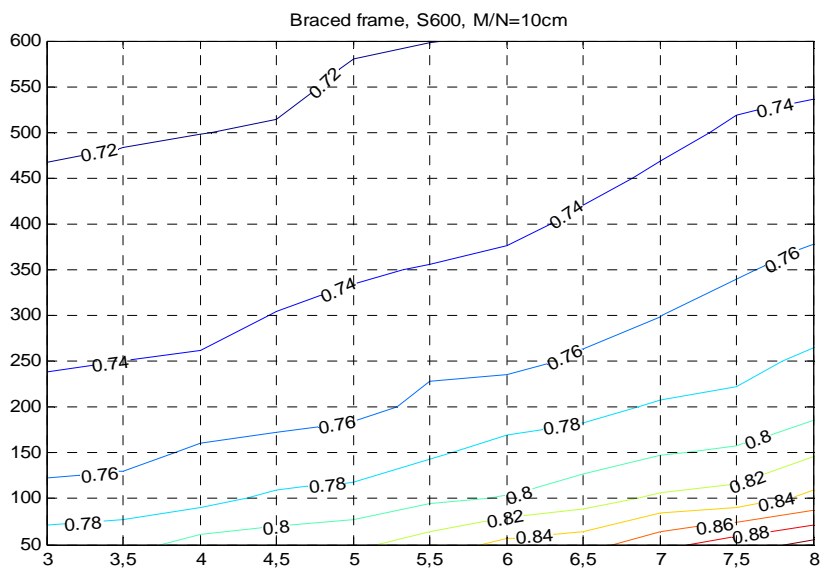

Fig.A20

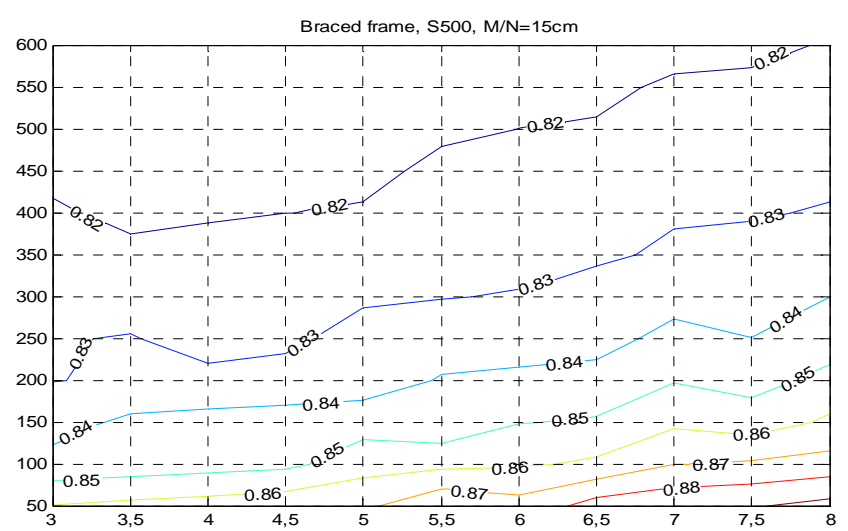

Fig.A22

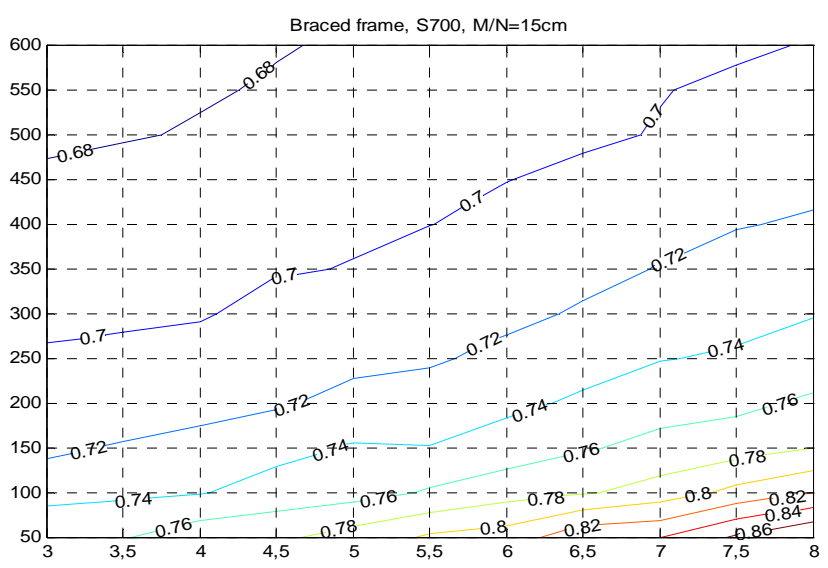

Fig.A24 
Charts 25 to 72. Columns in braced frames

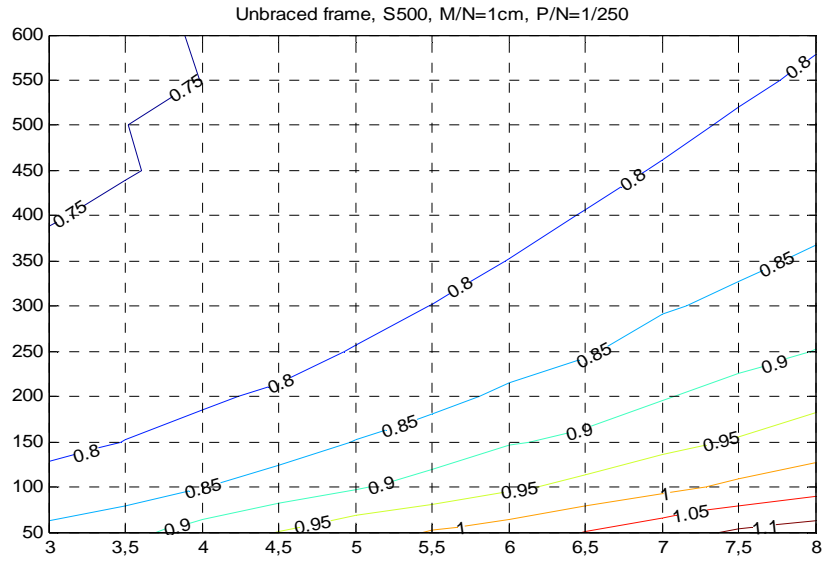

Fig.A25

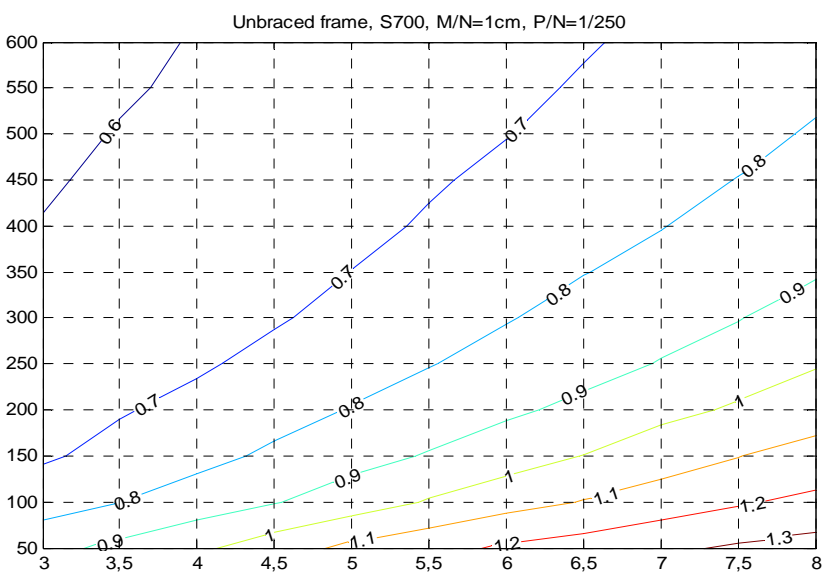

Fig.A27

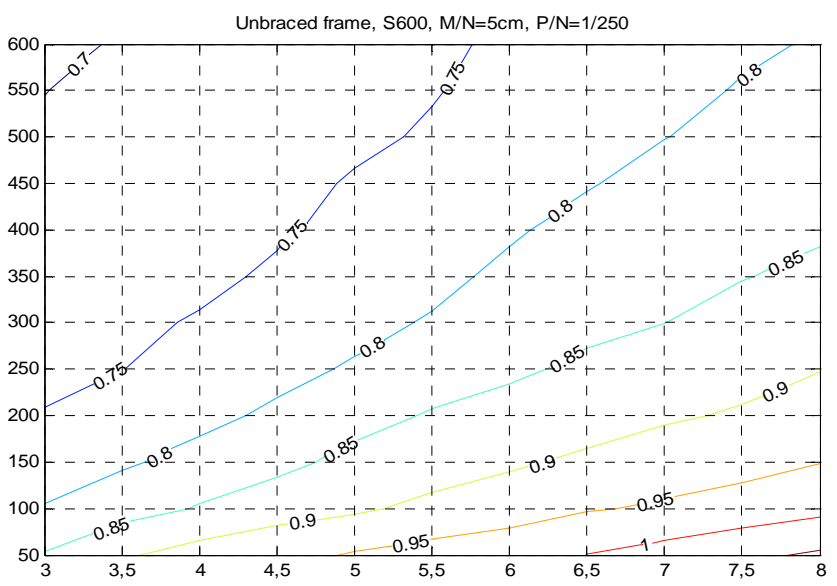

Fig.A29

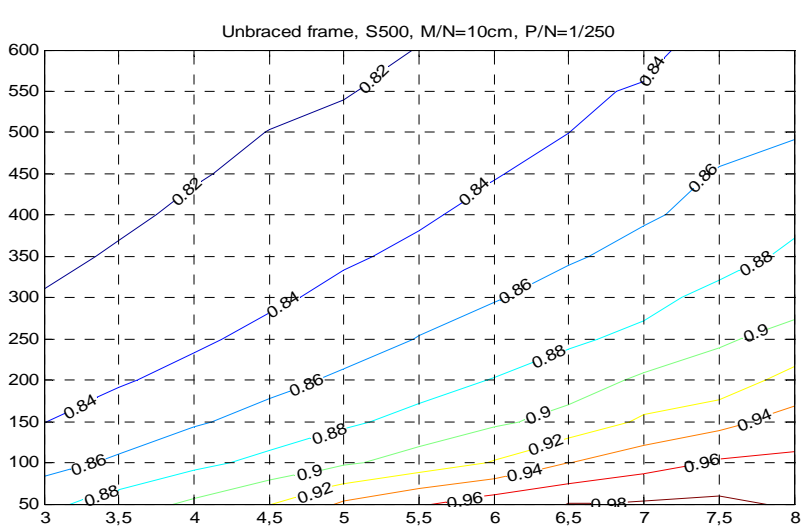

Fig.A31

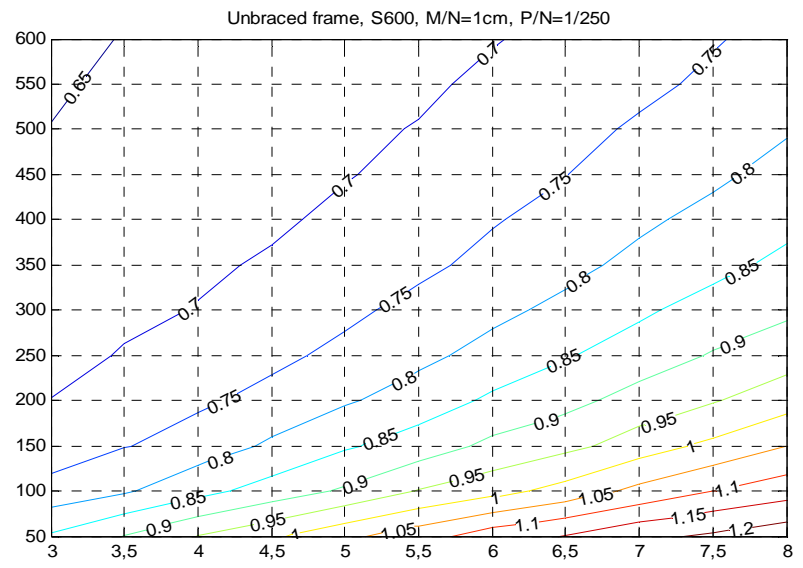

Fig.A26

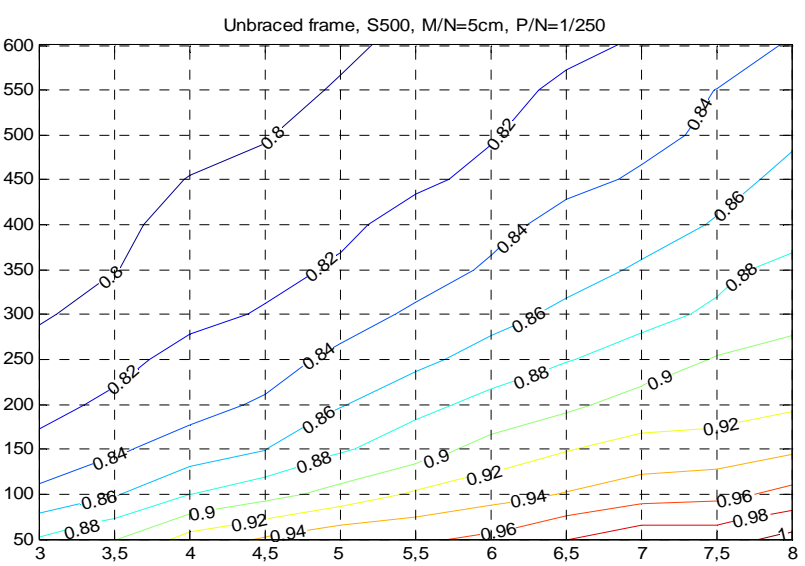

Fig.A28

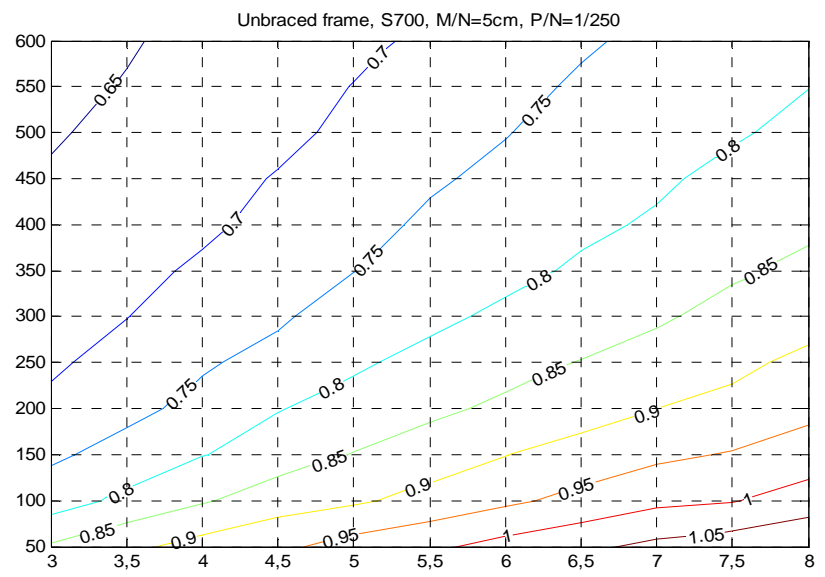

Fig.A30

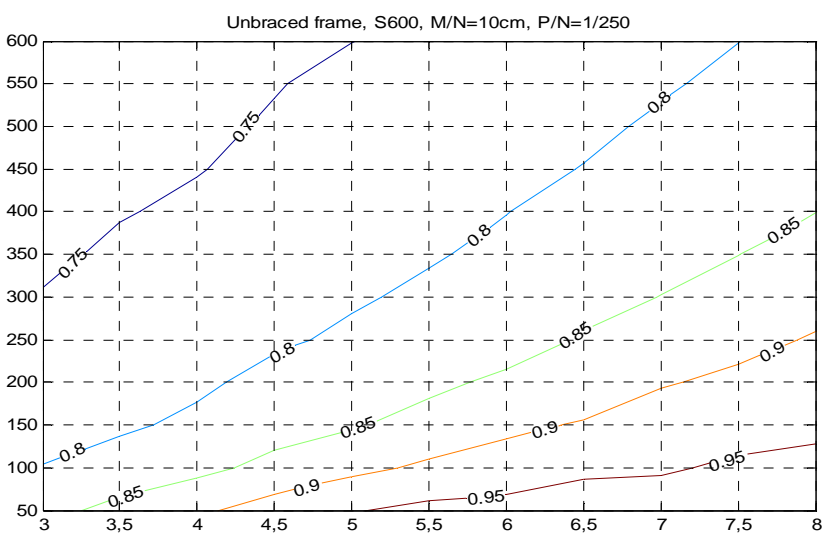

Fig.A32 


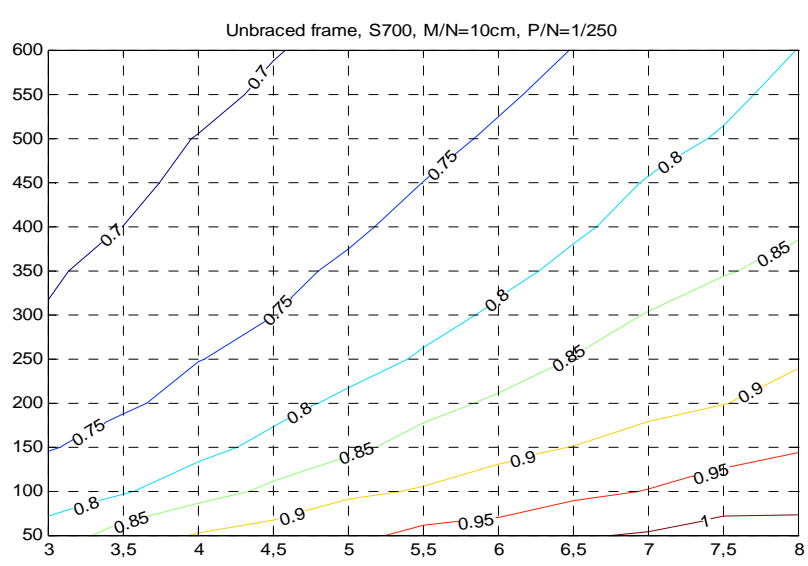

Fig.A33

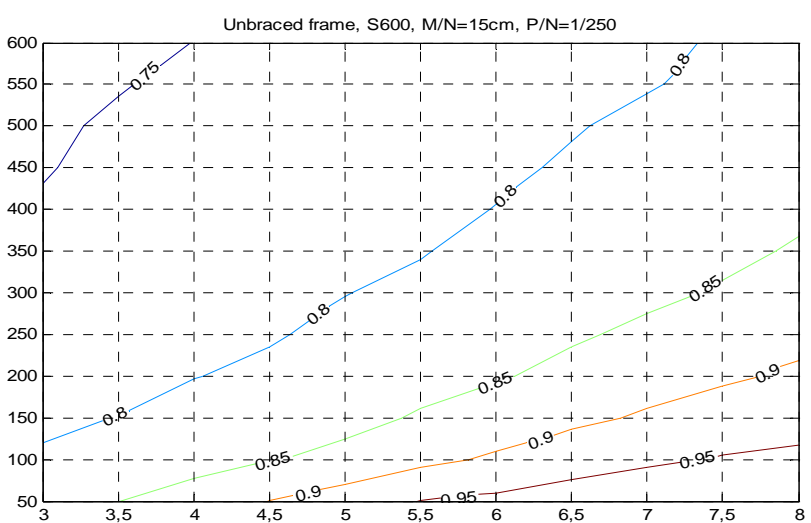

Fig.A35

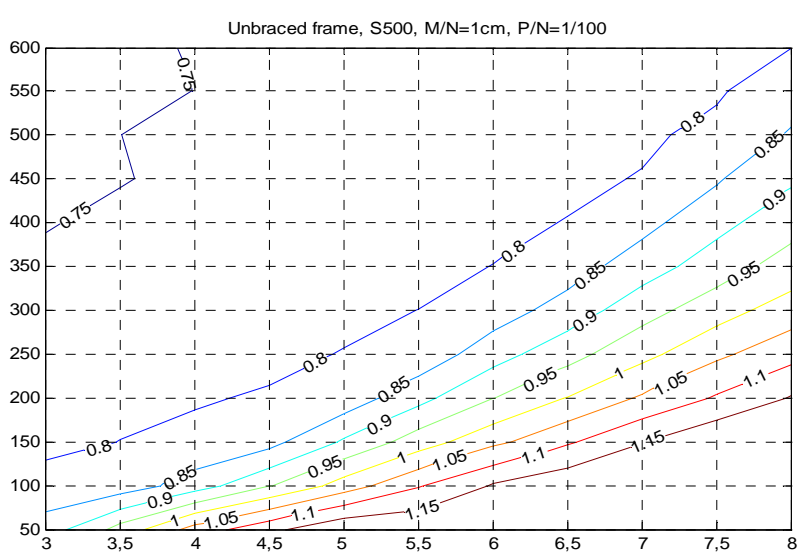

Fig.A37

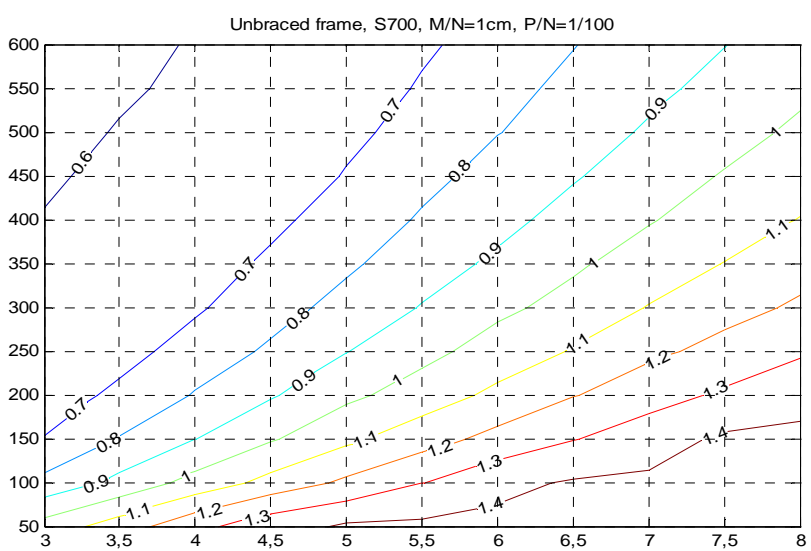

Fig.A39

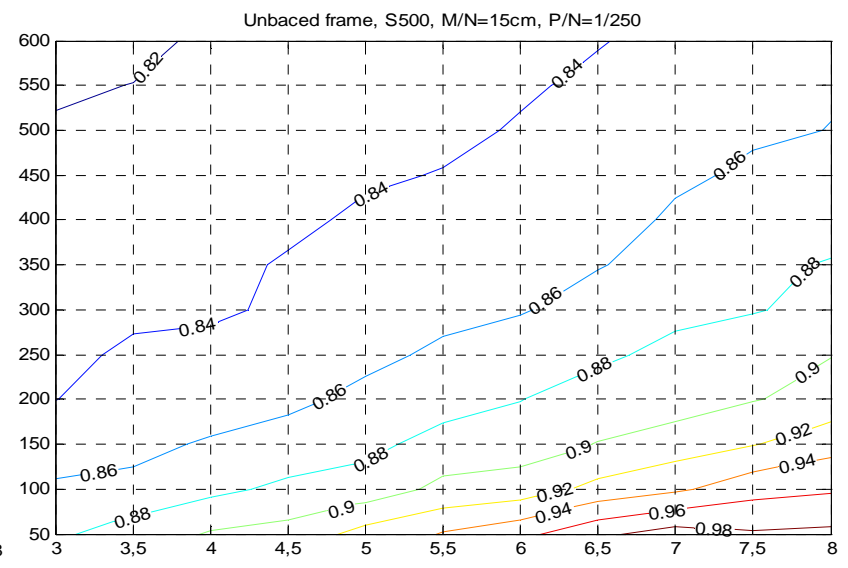

Fig.A34

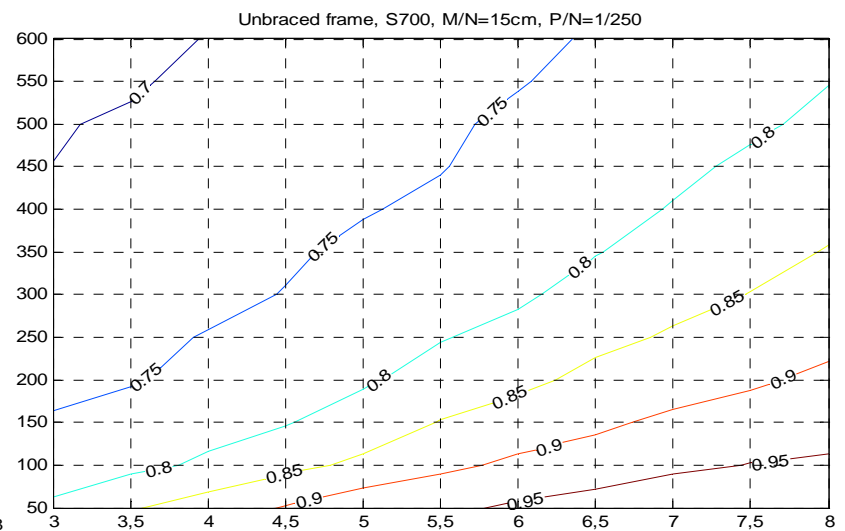

Fig.A36

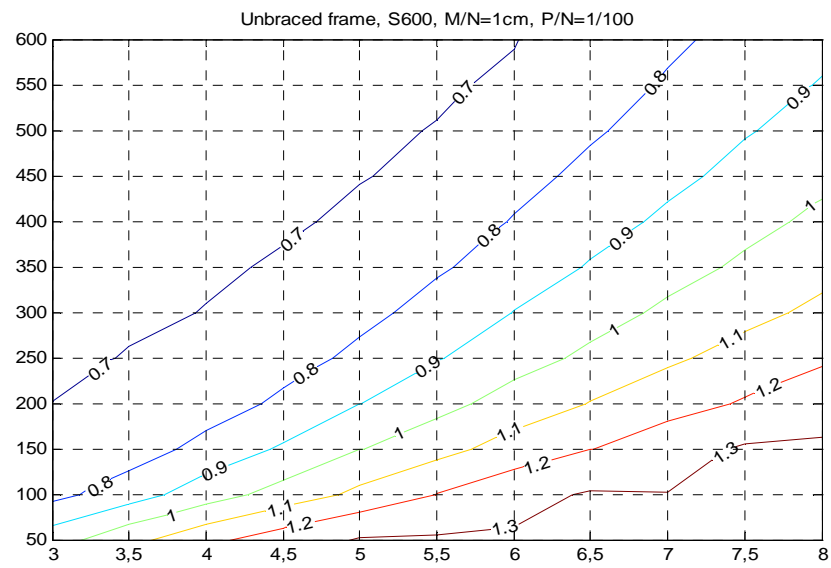

Fig.A38

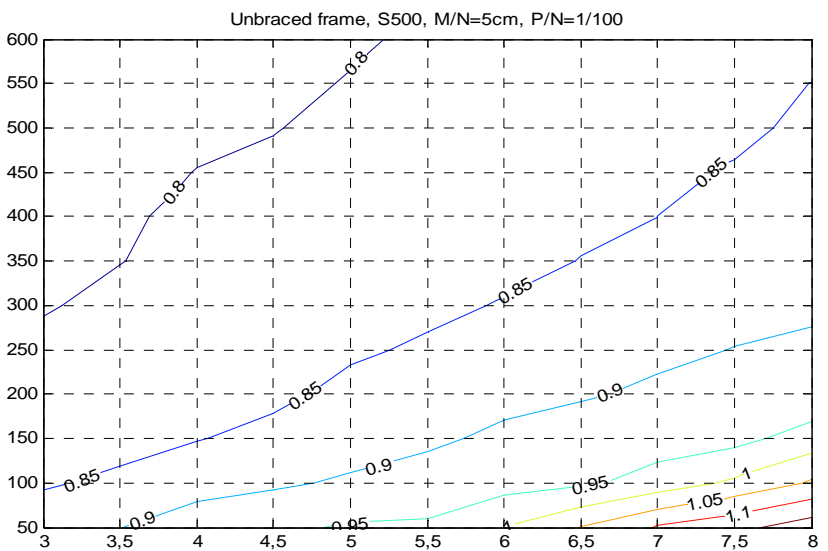

Fig.A40 


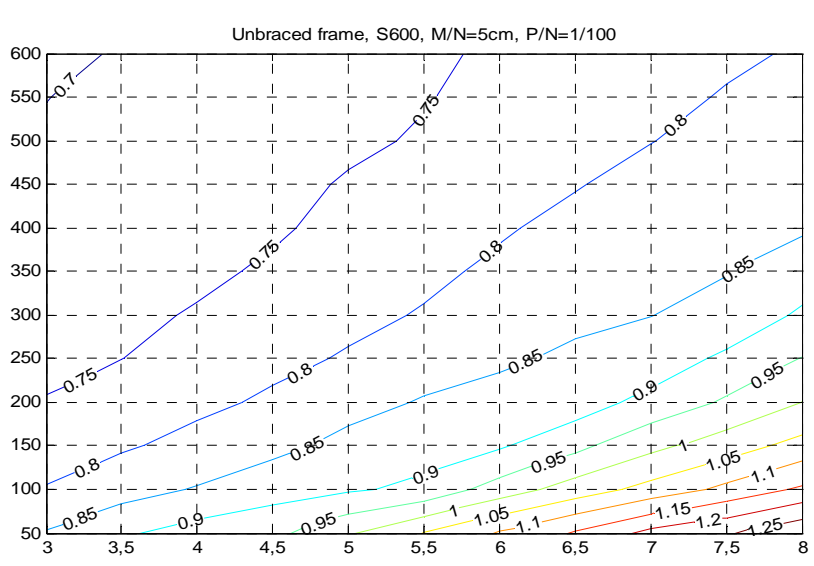

Fig.A41

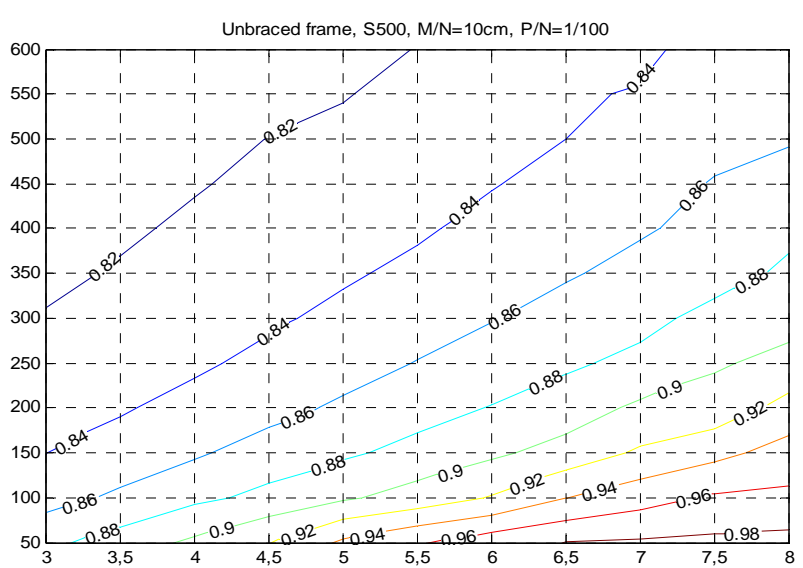

Fig.A43

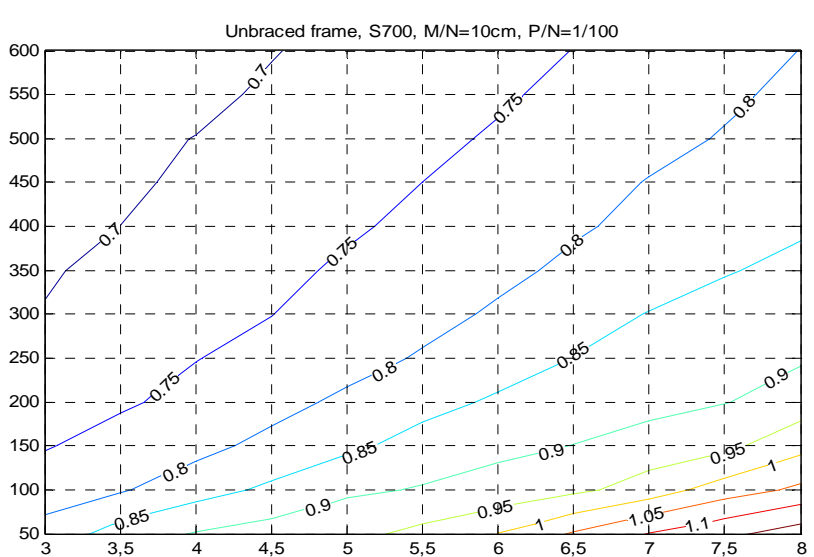

Fig.A45

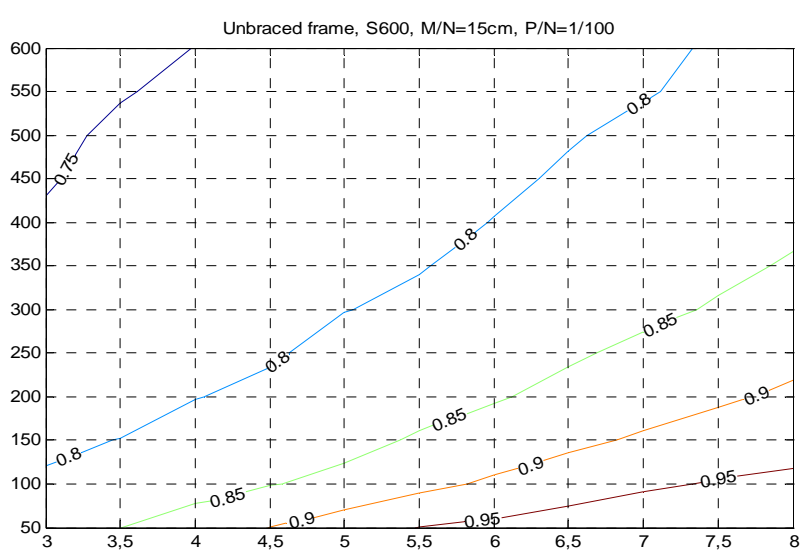

Fig.A47

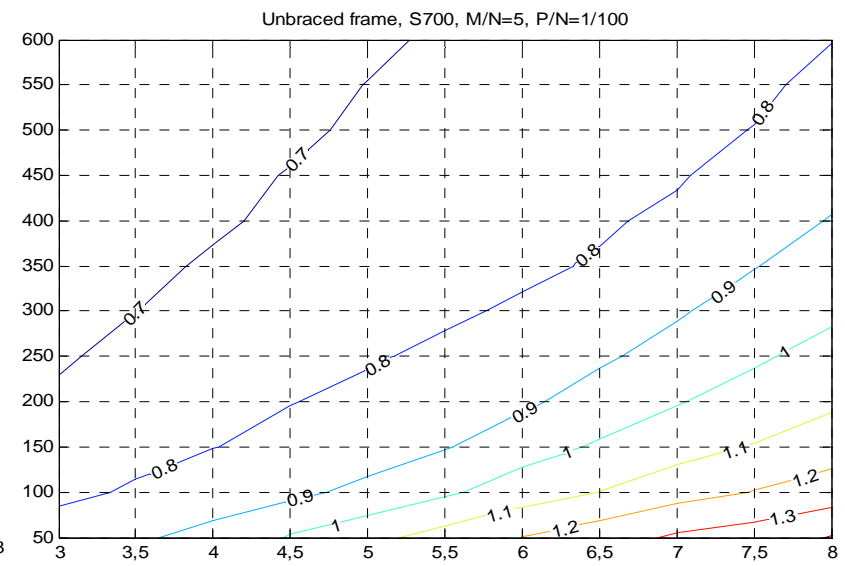

Fig.A42

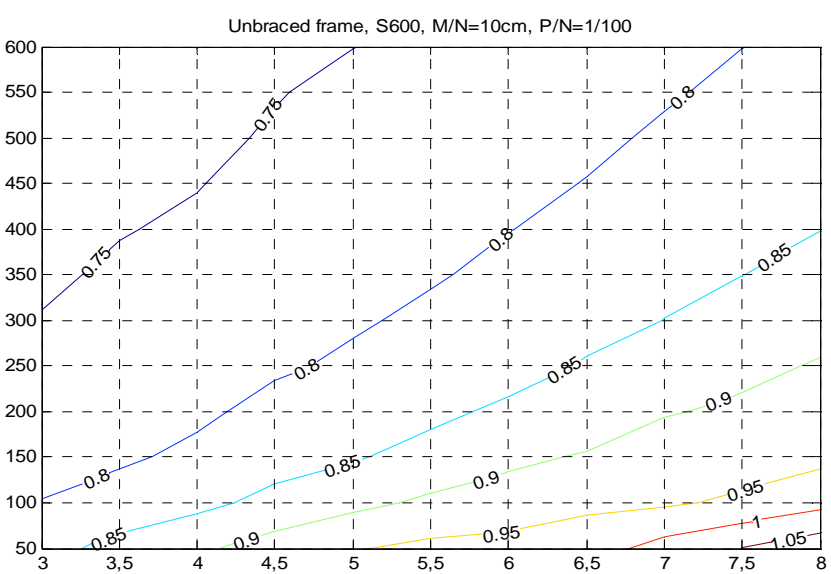

Fig.A44

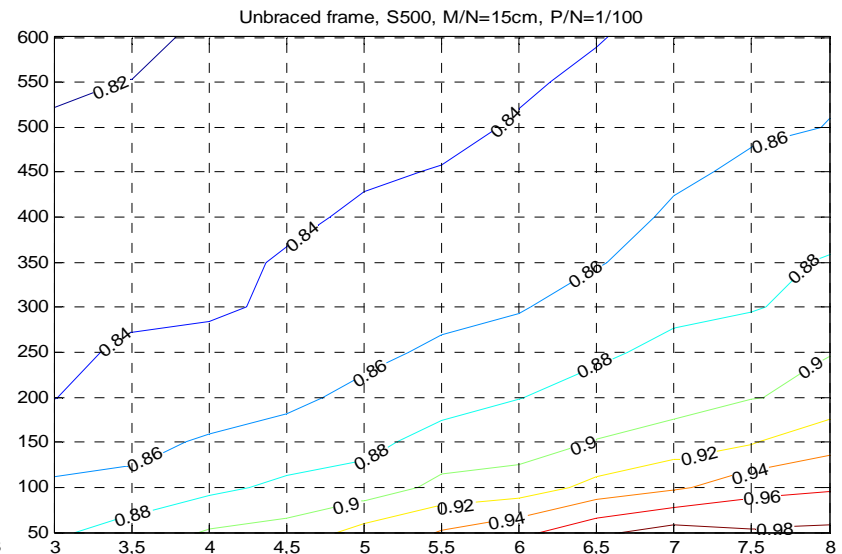

Fig.A46

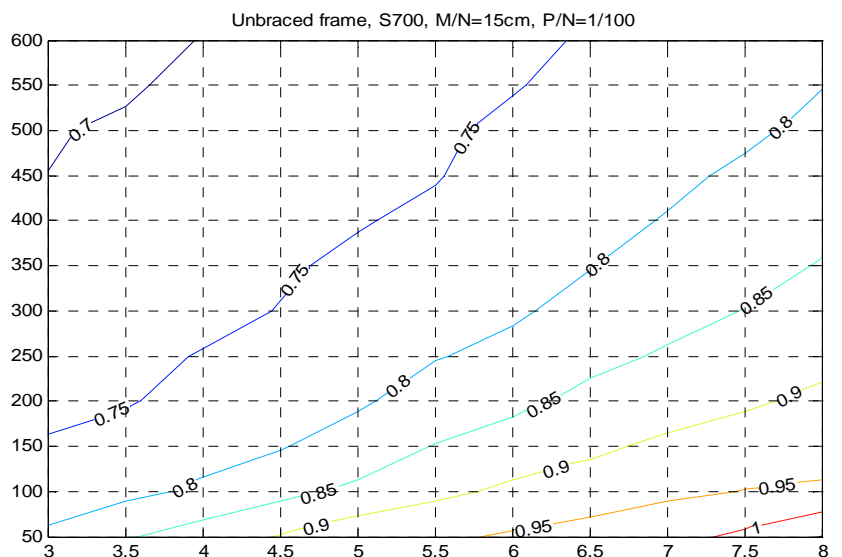

Fig.A48 


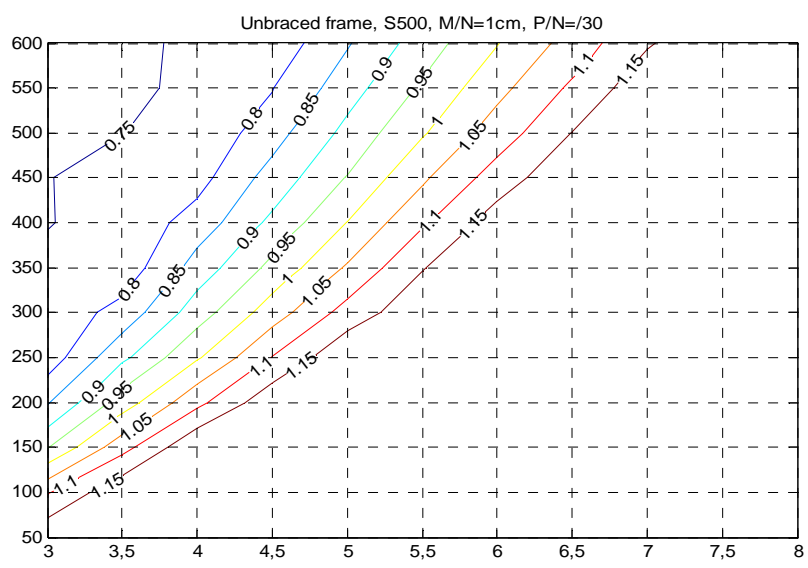

Fig.A49

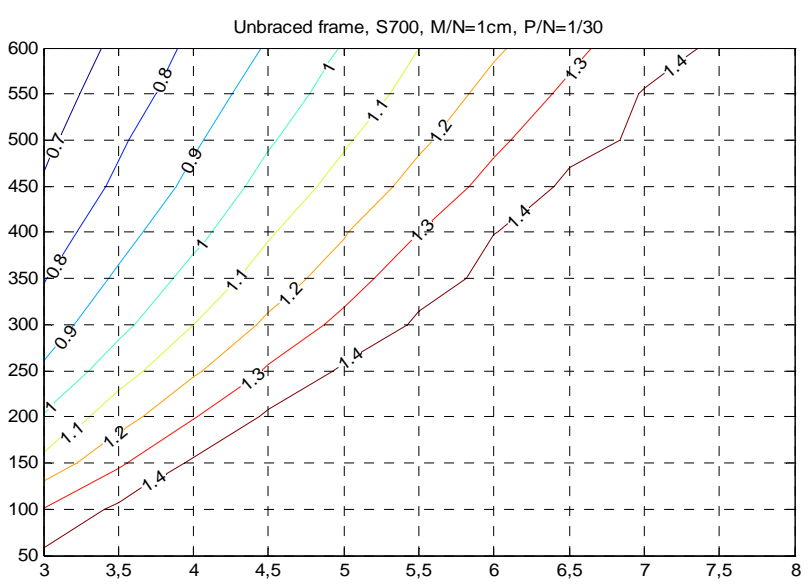

Fig.A51

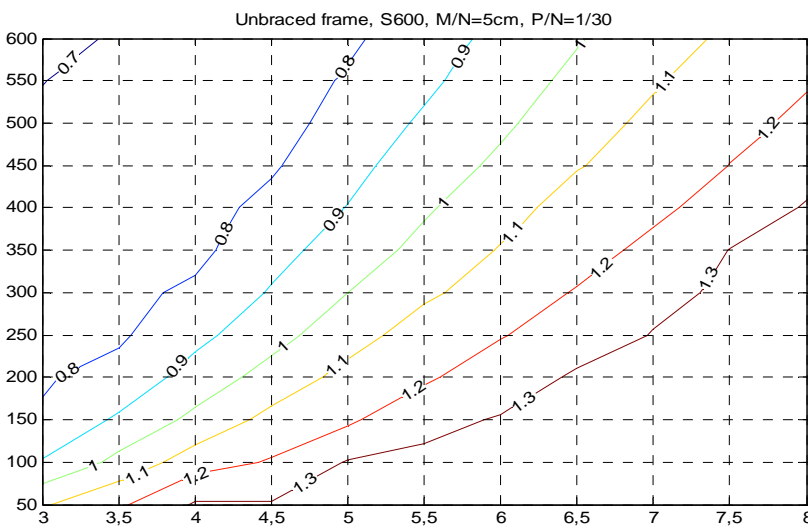

Fig.A53

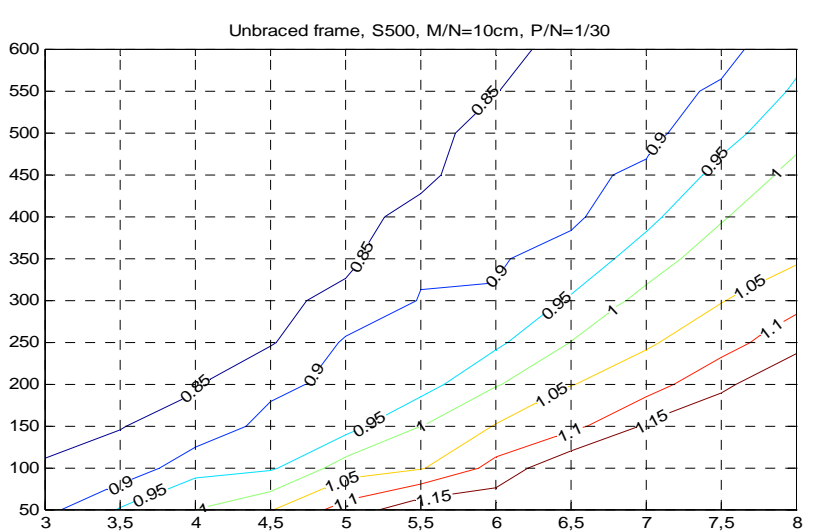

Fig.A55

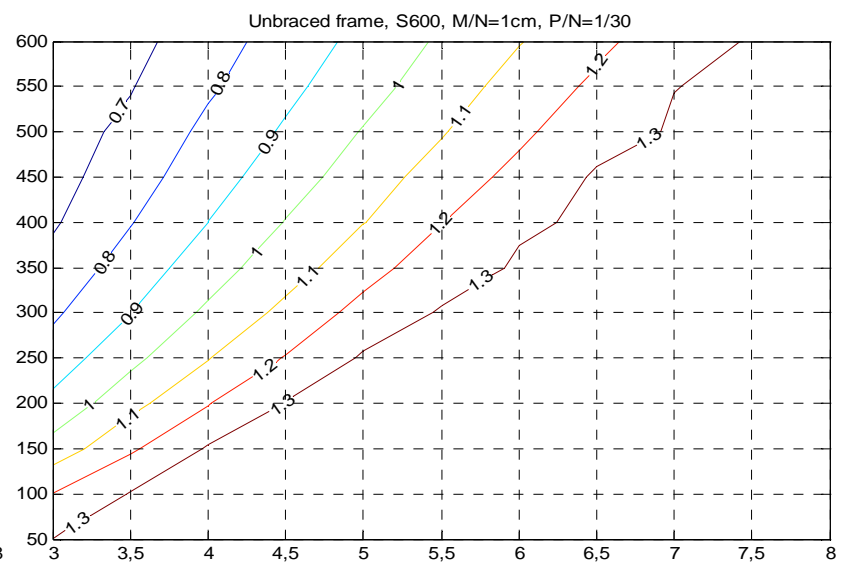

Fig.A50

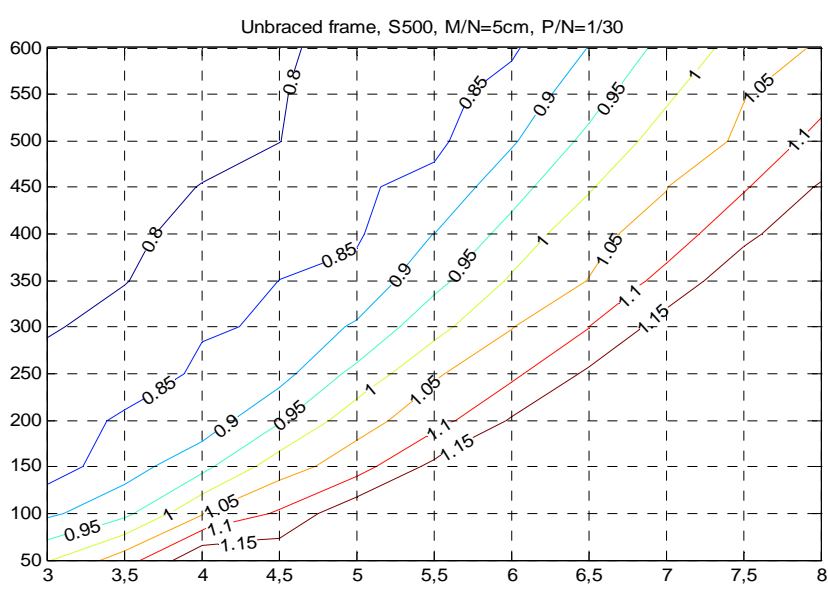

Fig.A52

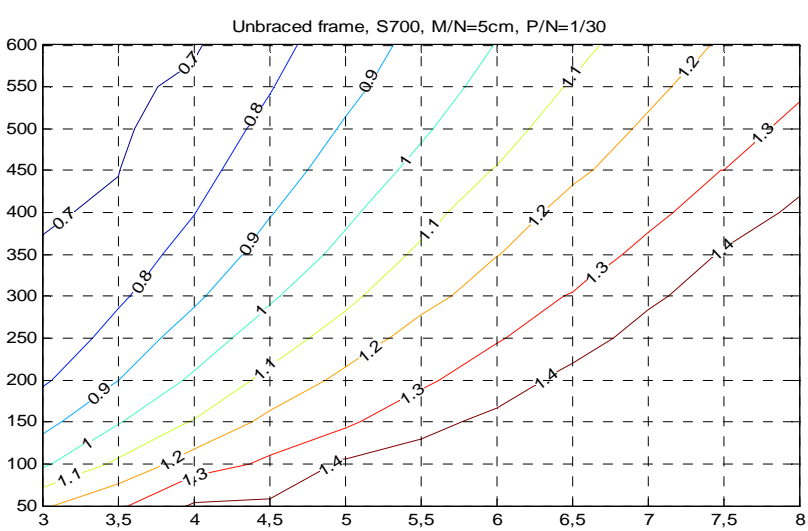

Fig.A54

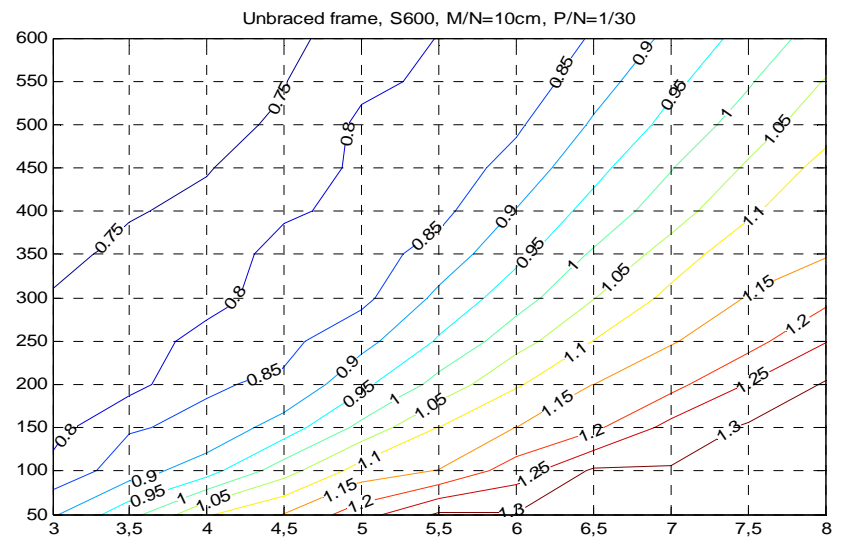

Fig.A56 


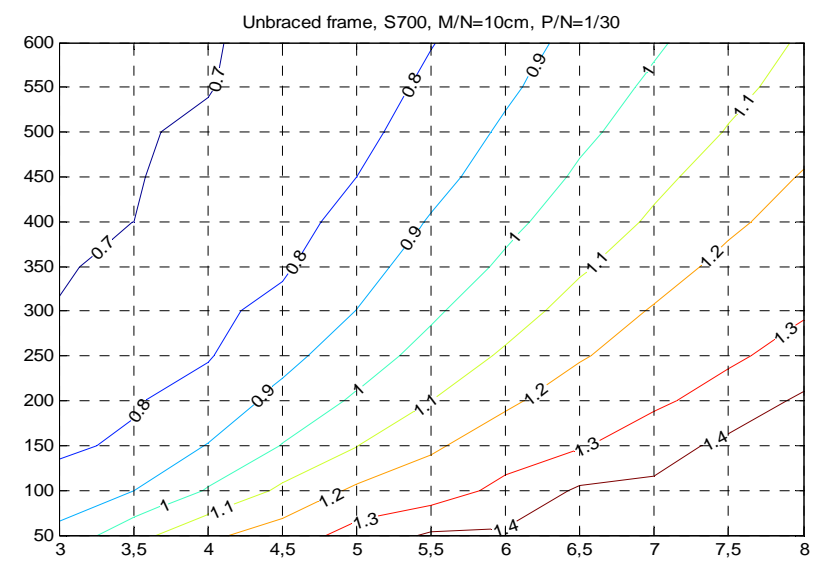

Fig.A57

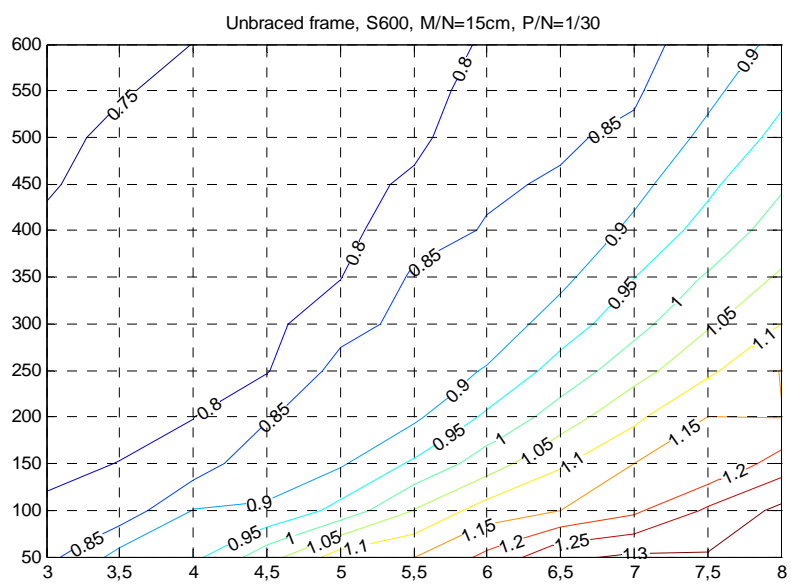

Fig.A59

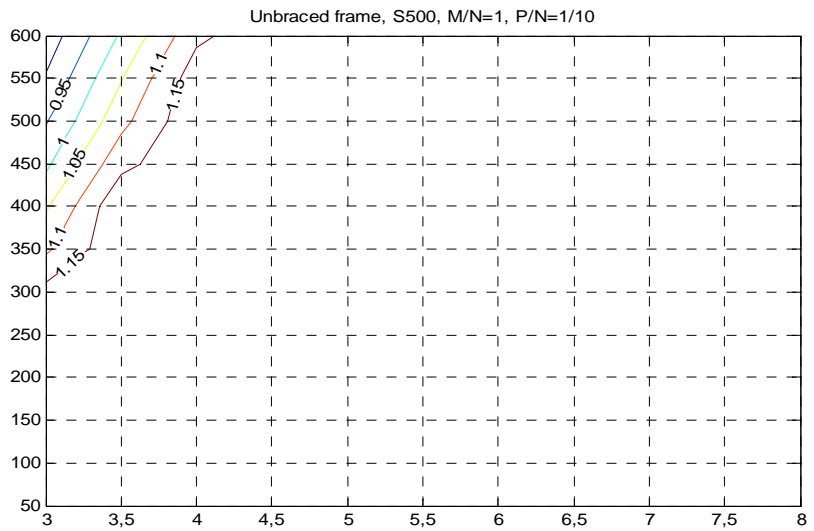

Fig.A61

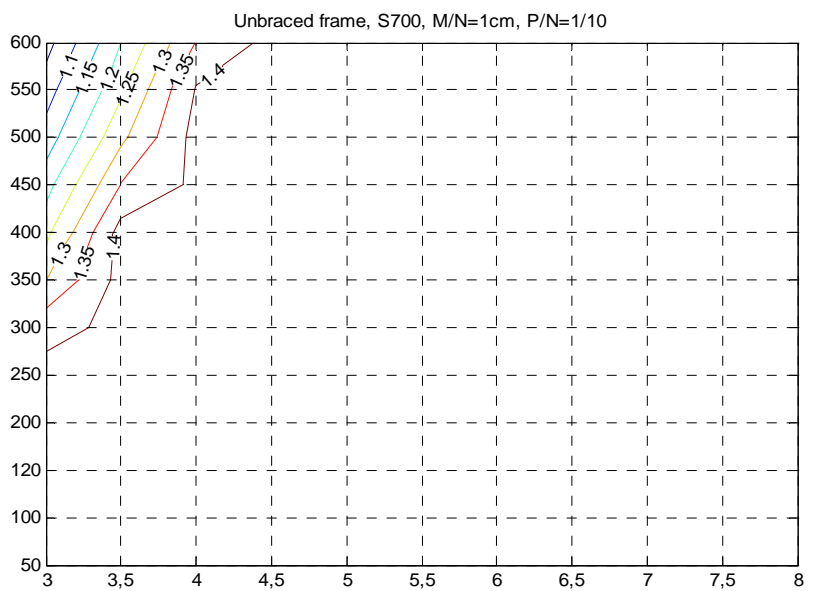

Fig.A63

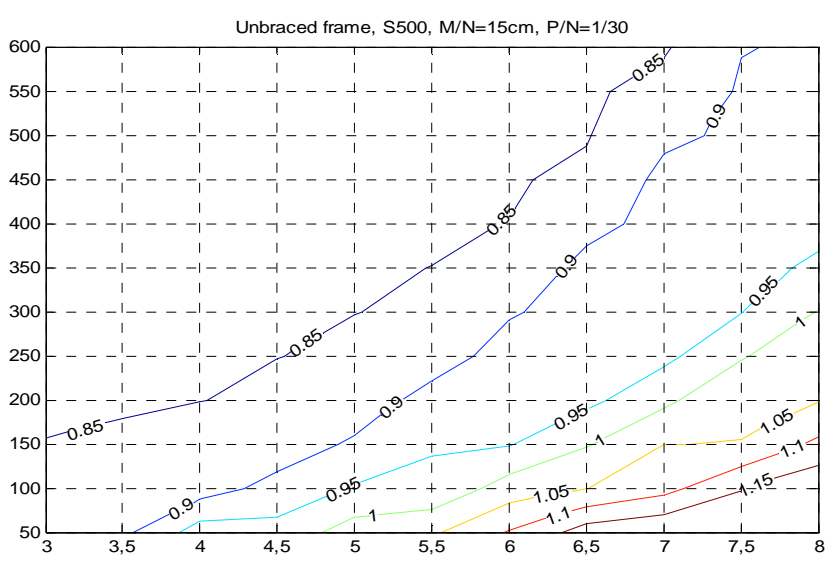

Fig.A58

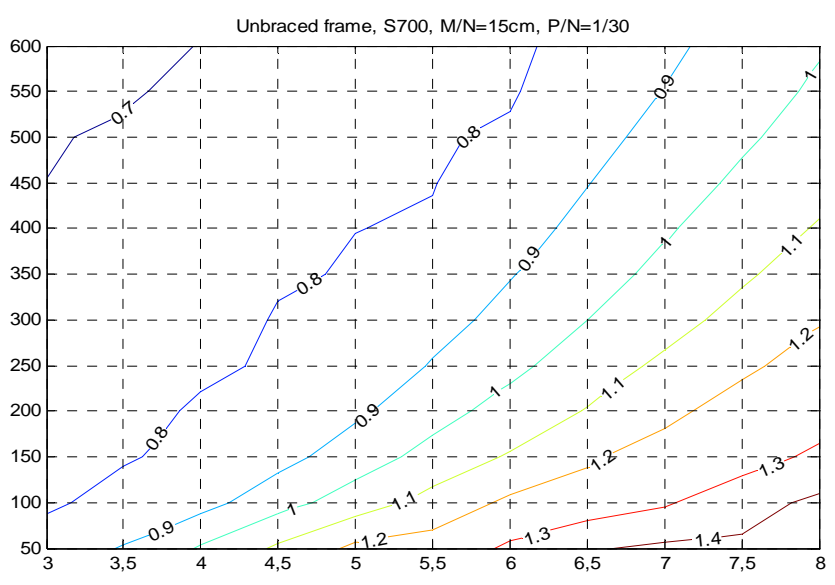

Fig.A60

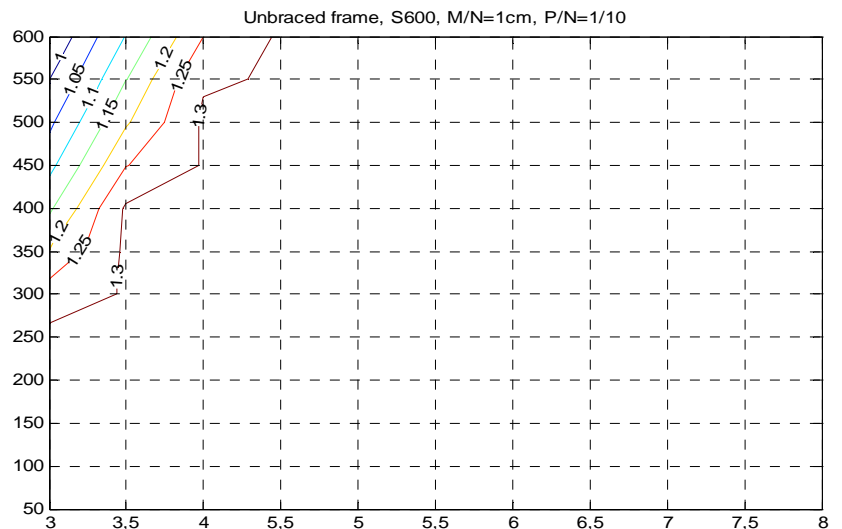

Fig.A62

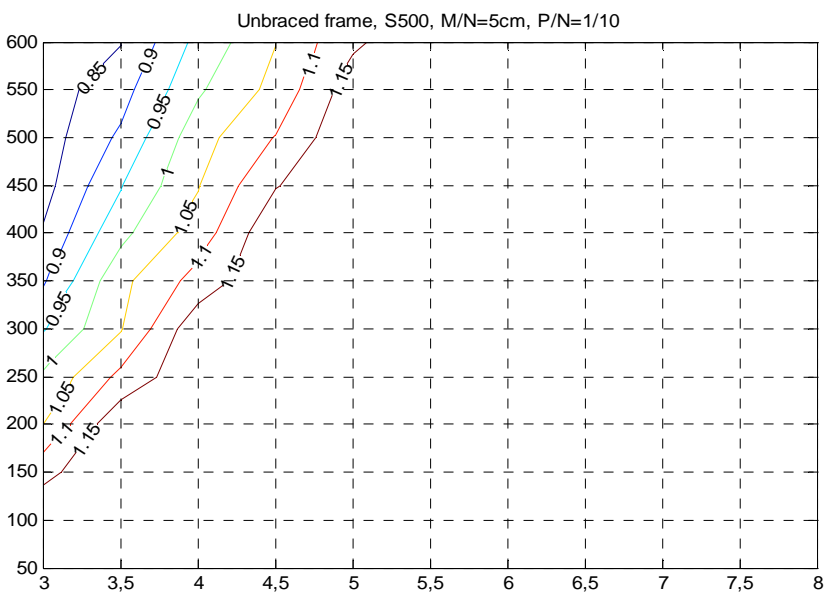

Fig.A64 


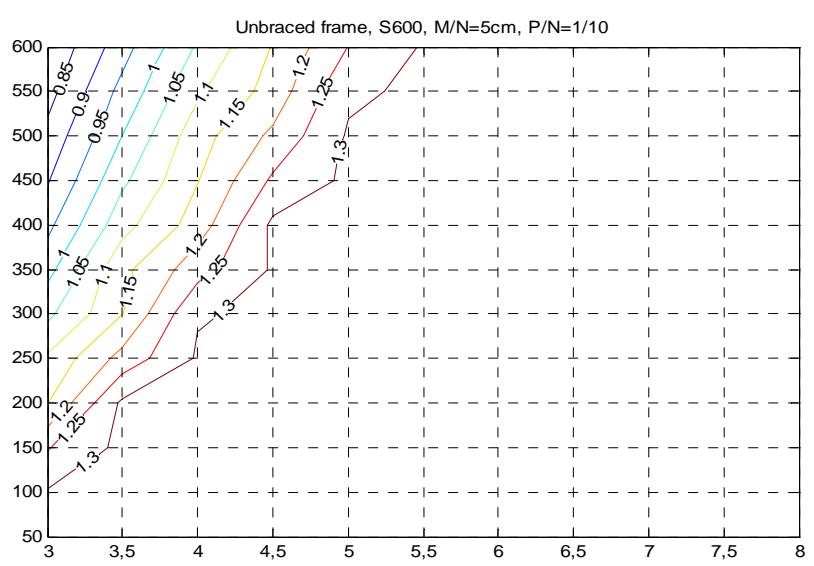

Fig.A65

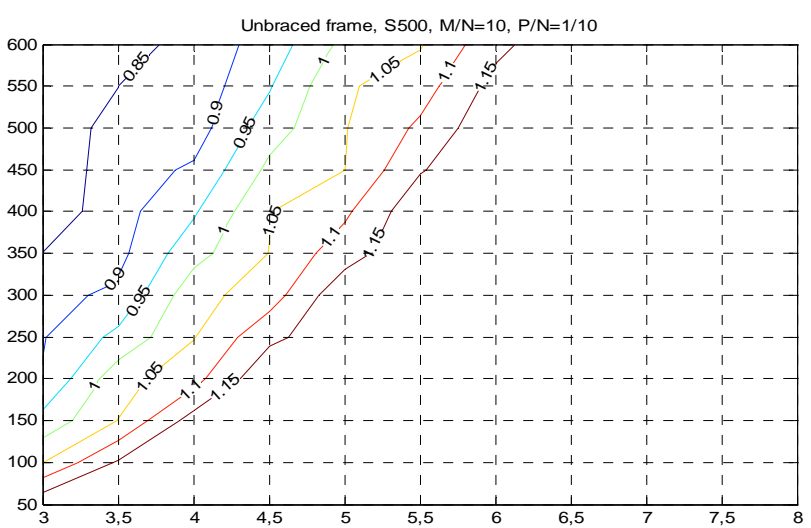

Fig.A67

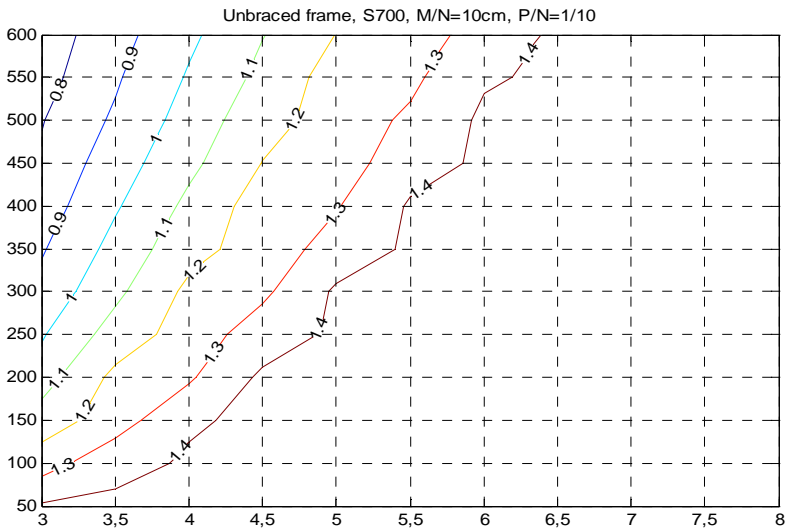

Fig.A69

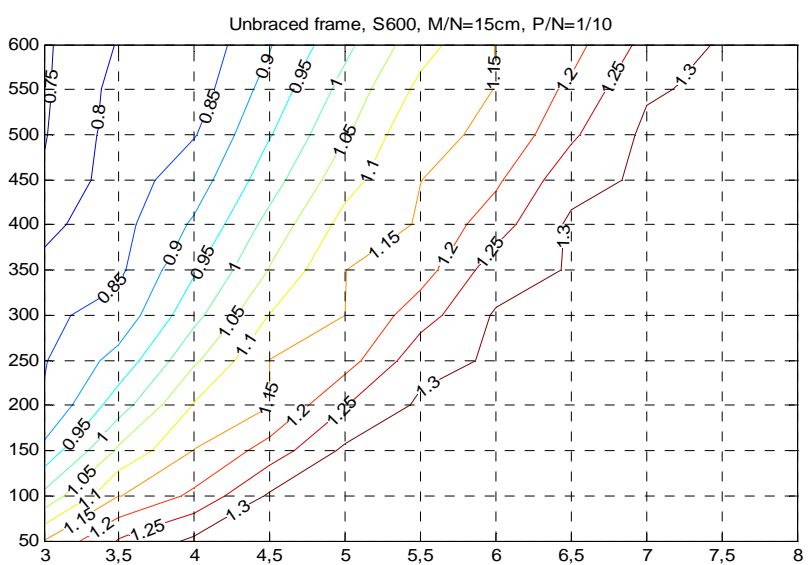

Fig.A71

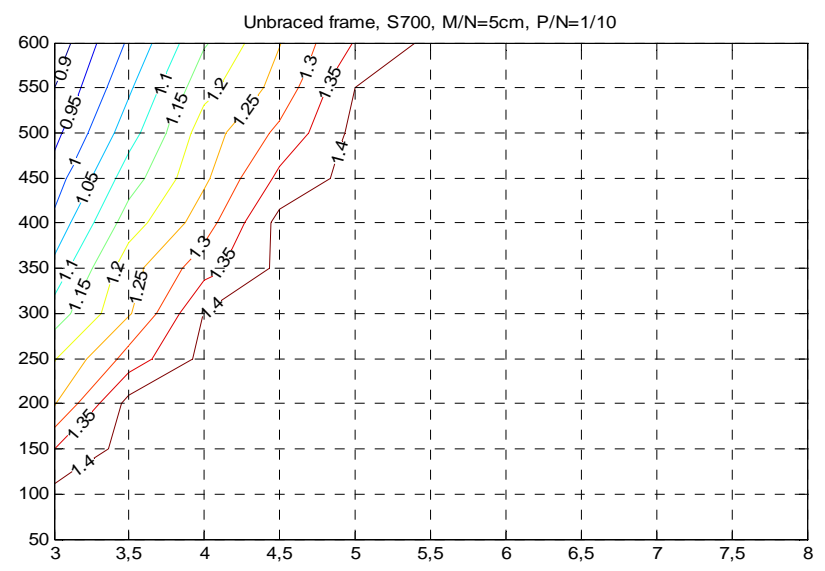

Fig.A66

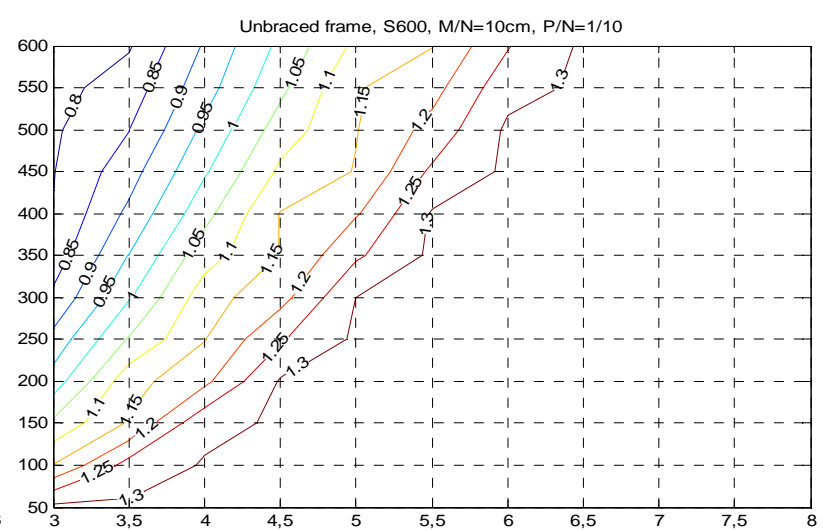

Fig.A68

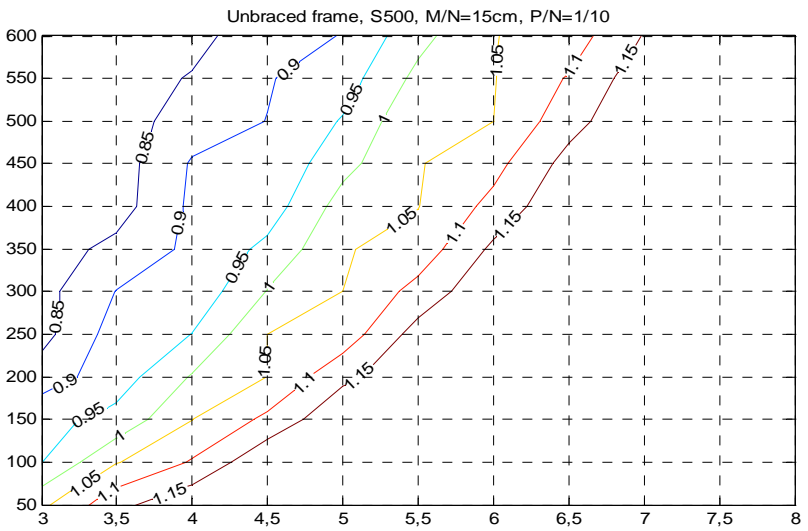

Fig.A70

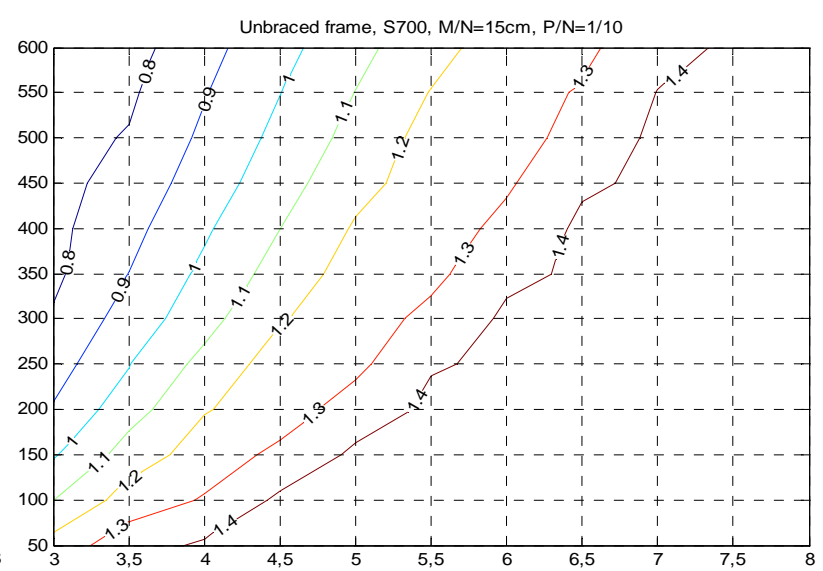

Fig.A72 